\title{
Review of the Asian Thaumastodinae (Coleoptera, Byrrhoidea, Limnichidae), with a phylogeny of the genera
}

\author{
Hiroyuki YOSHITOMI \\ Ehime University Museum, Bunkyo 3, Matsuyama, 790-8577 Japan. \\ Email: hymushi@agr.ehime-u.ac.jp \\ urn:1sid:zoobank.org:author:744FA6FC-2D84-41B7-8A6C-C1611CC68EE1
}

\begin{abstract}
The Asian species of the subfamily Thaumastodinae Champion, 1924 are reviewed. Seven new species are described: Acontosceles borneensis sp. nov., Pseudeucinetus papuanus sp. nov., Mexico ogasawaraensis sp. nov., M. baliensis sp. nov., M. papuanus sp. nov., M. palauensis sp. nov. and M. borneensis sp. nov. The genus Babalimnichus Satô, 1994 is treated as a junior synonym of the genus Mexico Spilman, 1972, and three known species of the genus Babalimnichus are transferred to Mexico, viz. M. taiwanus (Satô, 1994) comb. nov., M. masamii (Satô, 1994) comb. nov. and M. splendens (Hernando \& Ribera, 2003) comb. nov. Additional specimen data are shown, and new distributional records are as follows: Acontosceles chujoi Yoshitomi \& Satô, 2005 from Vietnam; A. zetteli Pütz, 2008 from Laos; Pseudeucinetus javanicus Yoshitomi \& Putra, 2010 from Lombok Island; Mexico taiwanus (Satô, 1994) comb. nov. from Lutao, Lanhsu and the Yonaguni-jima Islands; and M. masamii (Satô, 1994) comb. nov. from Kume-jima. A species list of the subfamily Thaumastodinae is given, with ZooBank LSIDs. The phylogenetic relationships of the thaumastodine genera are discussed.
\end{abstract}

Keywords. Coleoptera, Limnichidae, Thaumastodinae, new species, new synonym, identification key, checklist.

Yoshitomi H. 2019. Review of the Asian Thaumastodinae (Coleoptera, Byrrhoidea, Limnichidae), with a phylogeny of the genera. European Journal of Taxonomy 583: 1-45. https://doi.org/10.5852/ejt.2019.583

\section{Introduction}

Limnichidae Erichson, 1846 (minute marsh-loving beetles), a 'shore beetle' family (Jäch 1998), includes both riparian and littoral species, and has about 400 known species in 37 genera (Hernando \& Ribera 2005a). This family is subdivided into four subfamilies (Limnichinae Erichson, 1846; Hyphalinae Britton, 1971; Cephalobyrrhinae Champion, 1925; and Thaumastodinae Champion, 1924) and has not been well studied taxonomically. Furthermore, the phylogenetic position of the family and its subfamilies is still not understood (Hernando \& Ribera 2005a). The phylogenetic placement of Limnichidae and its possible non-monophyly has been considered previously by many authors, both informally (e.g., Hinton 1939; Crowson 1978) and with cladistic analyses (e.g., Lawrence 1988; Beutel 1995). Costa et al. (1999) mentioned the phylogenetic position of the family and its subfamilies, but their relationships remained uncertain. The monophyly of the family Limnichidae was not supported, but the families Limnichidae, Dryopidae and Heteroceridae constitute a monophyletic clade. Kundrata et al. (2017) analysed the molecular phylogeny of Byrrhoidea and Buprestoidea, and three subfamilies (all except 
Hyphalinae) of the family Limnichidae were treated. The family Limnichidae was a paraphyletic group due to Chelonariidae and Heteroceridae.

Thaumastodinae Champion, 1924 (so-called 'jumping shore beetles') is one of four subfamilies of the family Limnichidae and is represented by five genera from the Palearctic, Oriental, Australian and Neotropical Regions (see Appendix 1). The members of this subfamily have interesting morphological characters, e.g., capable of jumping using the hind legs, elongate body shape, and large eyes situated dorsally and separated narrowly on the vertex. In fact, Heller (1921) mistakenly stated that the genus Pseudeucinetus Heller, 1921, the first representative of this subfamily, was a member of the family Melandryidae Leach, 1815, and it was Champion (1924b) who recognized it as a member of Limnichidae. Zoogeographically, a disjunct distribution between the Oriental and Neotropical Regions (except for some species in the Palearctic and Australian Regions) is shown, but the reason for this distributional pattern is unclear (Hernando \& Ribera 2005a). The Neotropical species have been relatively well studied (Spilman 1959, 1966; Wooldridge 1988; Skelley 2005), but the Oriental ones have not.

In this paper, I review the Asian genera and species of the subfamily Thaumastodinae and discuss the phylogenetic relationships of the genera.

\section{Material and methods}

\section{Taxonomy}

General observations and dissections were made using a Leica MZ95 stereo microscope. Microstructures of the dissected parts were studied in pure glycerine under an Olympus BH-2 compound microscope. After observation, the dissected parts were mounted on the same card as the specimen. Photographs were taken using a Leica MZ95 and combined in Helicon ${ }^{\circledR}$ Focus ver. 4.70.5 Pro (Helicon Soft ${ }^{\circledR}$ Limited). Some structures were observed with an SEM (Hitachi S-225), after coating with gold. Values in parentheses refer to the average.

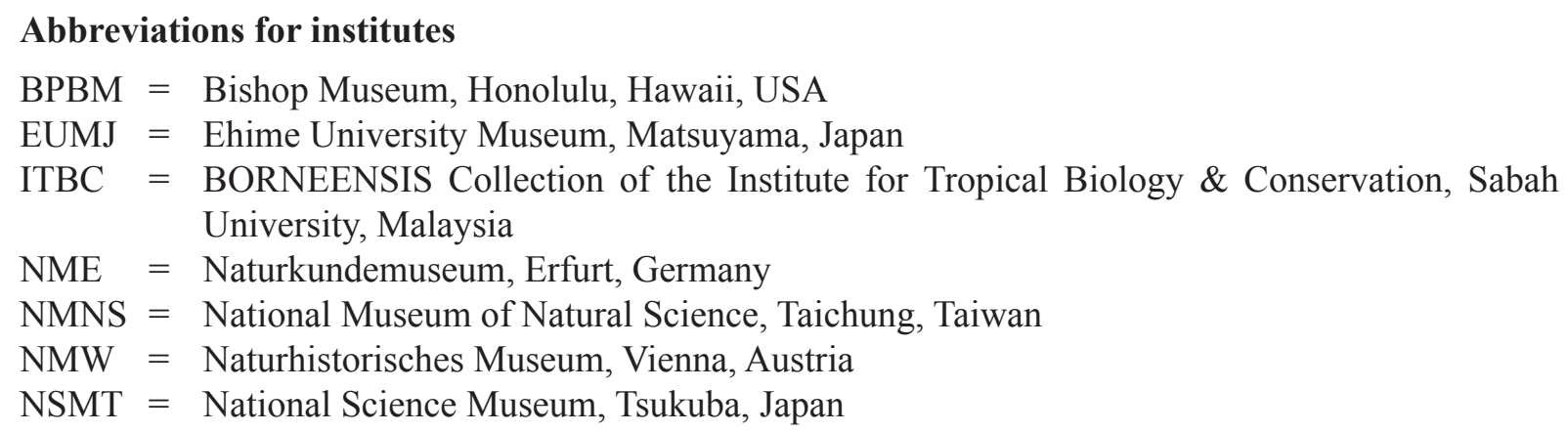

\section{Abbreviations for body measurements}

$\mathrm{EL}=$ length of elytra at suture

$\mathrm{EW}=$ maximum width of elytra

HW $=$ head width across eyes

$\mathrm{PL}=$ mesal length of pronotum

$\mathrm{PW}=$ maximum width of pronotum

$\mathrm{TL}=$ total length $(\mathrm{PL}+\mathrm{EL})$

\section{Abbreviations for male genitalia measurements (Fig. 1)}

$\mathrm{BL}=$ length of basal piece

$\mathrm{LL}=$ length of lateral lobe

ML = length of median lobe 


\section{Phylogeny}

For the phylogenetic analyses, I selected four genera from the subfamily as ingroups and one genus of the family Limnichidae as an outgroup:

Ingroups: Acontosceles Champion, 1924; Pseudeucinetus Heller, 1921; Mexico Spilman, 1972; and Martinius Spilman, 1959 (Thaumastodinae)

Outgroup: Limnichus Latreille, 1829 (Limnichinae)

Fourteen characters were selected for phylogenetic analysis (Appendix 2). Characters were coded as ' 0 ', ' 1 ' or ' 2 ', and the data matrix is shown in Appendix 3. WinClada ver. 10.00.08 (Nixon 2002) and NONA ver. 2.0 (Goloboff 1999) were used for the analyses.

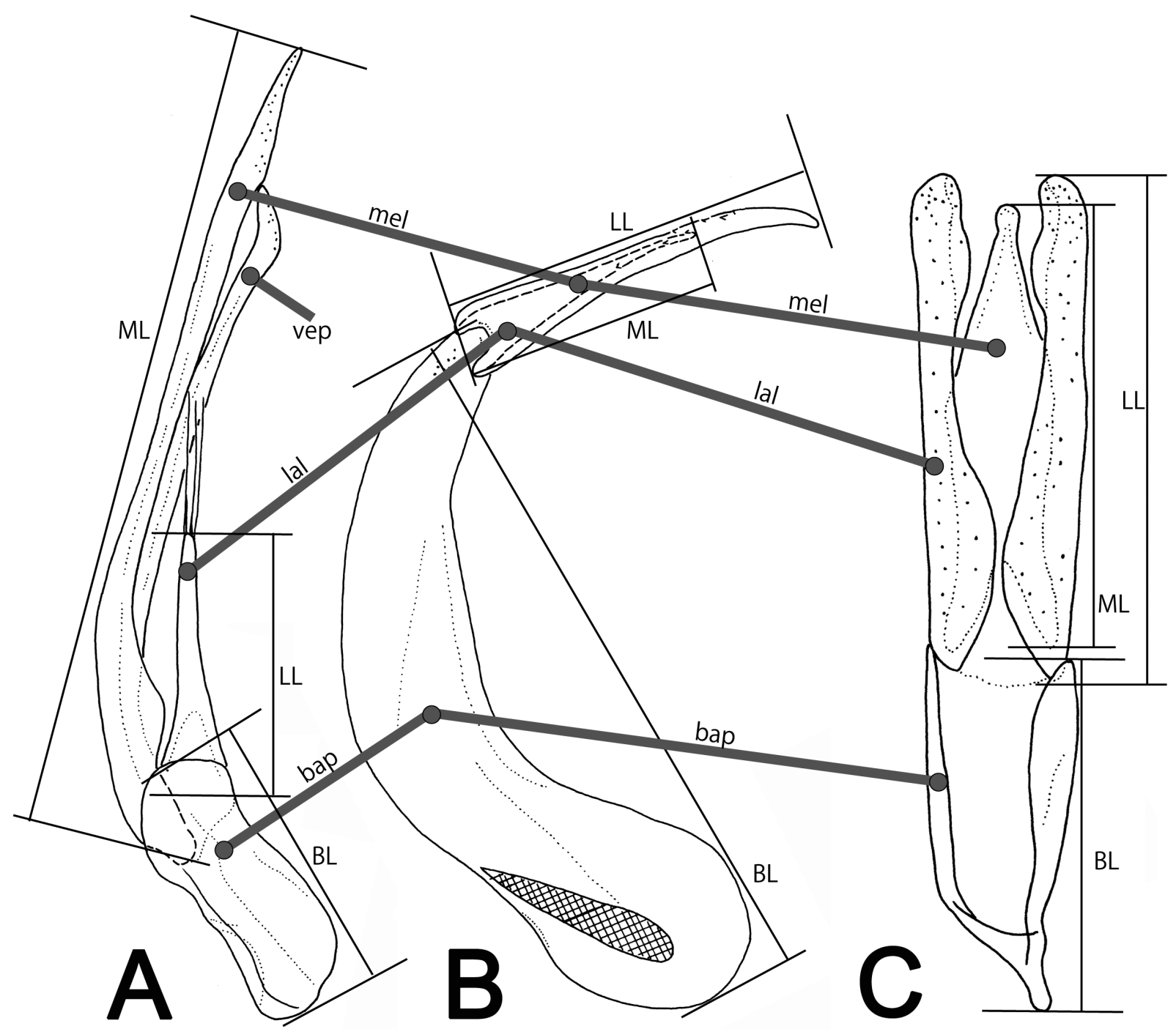

Fig. 1. Aedeagus, showing the terminology and the method of measurements. A. Mexico Spilman, 1972, left lateral view. B. Acontosceles Champion, 1924, left lateral view. C. Pseudeucinetus Heller, 1921, ventral view. Abbreviations: $b a p=$ basal piece; $1 \mathrm{al}=$ lateral lobe; $\mathrm{mel}=$ median lobe; vep = ventral plate; $\mathrm{BL}=$ length of basal piece; $\mathrm{LL}=$ length of lateral lobe; $\mathrm{ML}=$ length of median lobe. 


\section{Results}

\section{Taxonomic account}

Class Insecta Linnaeus, 1758

Order Coleoptera Linnaeus, 1758

Suborder Polyphaga Emery, 1886

Series Elateriformia Crowson, 1960

Superfamily Byrrhoidea Latreille, 1804

Family Limnichidae Erichson, 1846

Subfamily Thaumastodinae Champion, 1924

Thaumastodinae Champion, 1924a: 25 (type genus: Thaumastodus Champion, 1924 [junior synonym of Pseudeucinetus Heller, 1921]).

Thaumastodinae - Spilman 1959: 111; 1972: 113 [key to genera]. — Skelley 2005: 119.

\section{Diagnosis}

Body elongate to oblong, slightly shining, closely covered with short suberect setae. Eyes (Fig. 2) large, situated on dorso-lateral parts of head, separated narrowly on vertex. Antennae short to relatively short, 7- or 11-segmented, compactly articulated in terminal 6 antennomeres. Basal margin of elytra not crenulate. Tarsal formula 4-4-4 or 4-5-5. Hind legs long, capable of jumping; hind tibiae bearing spines. Sexual dimorphism distinct in fore tarsi (genus Pseudeucinetus) or in sternite VII.
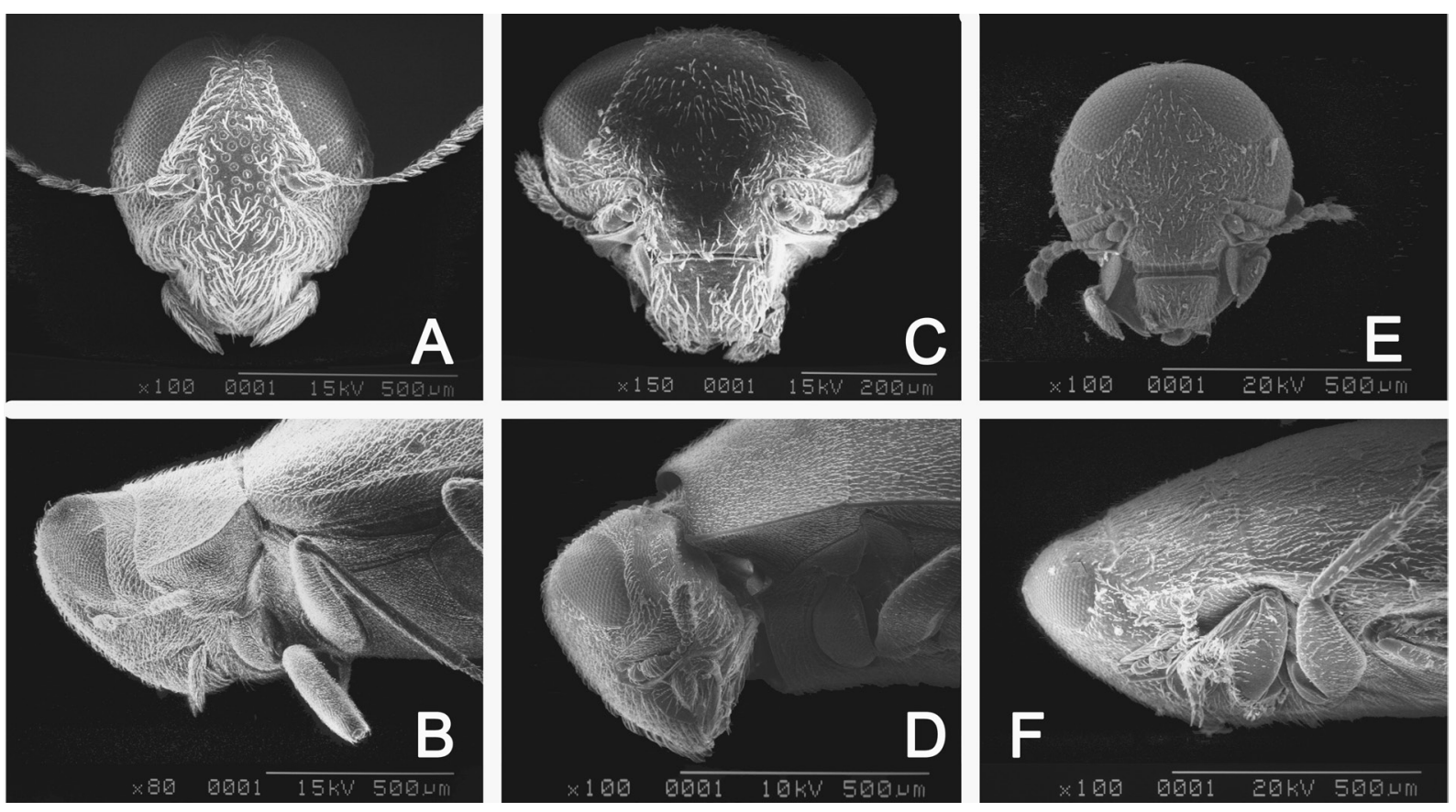

Fig. 2. Head in frontal (A, C, E) and lateral (B, D, F) views. A, D. Acontosceles chujoi Yoshitomi \& Satô, 2005. B, E. Mexico masamii (Satô, 1994). C, F. Pseudeucinetus zygops Heller, 1921. 


\section{Key to genera of the subfamily Thaumastodinae}

1. Tarsal formula 4-5-5; legs long and slender; antennal insertions situated near eyes (Fig. 2A); metaventrite short, not covering metacoxa (Fig. 3A); in freshwater environments; Oriental Region. Acontosceles Champion, 1924

- Tarsal formula 4-4-4; legs long and stout; antennal insertions situated near mandibles (Fig. 2C, E); metaventrite projecting posteriorly, covering metacoxa (Fig. 3B); in both fresh- and saltwater environments.

2. Frons distinctly projecting anteriorly, narrow (Fig. 2E-F); male fore tarsi enlarged (Fig. 3E); in freshwater environments; Oriental Region.

Pseudeucinetus Heller, 1921

- Frons gently projecting anteriorly, wide (Fig. 2C-D); male fore tarsi normal; on rocky seashores ...
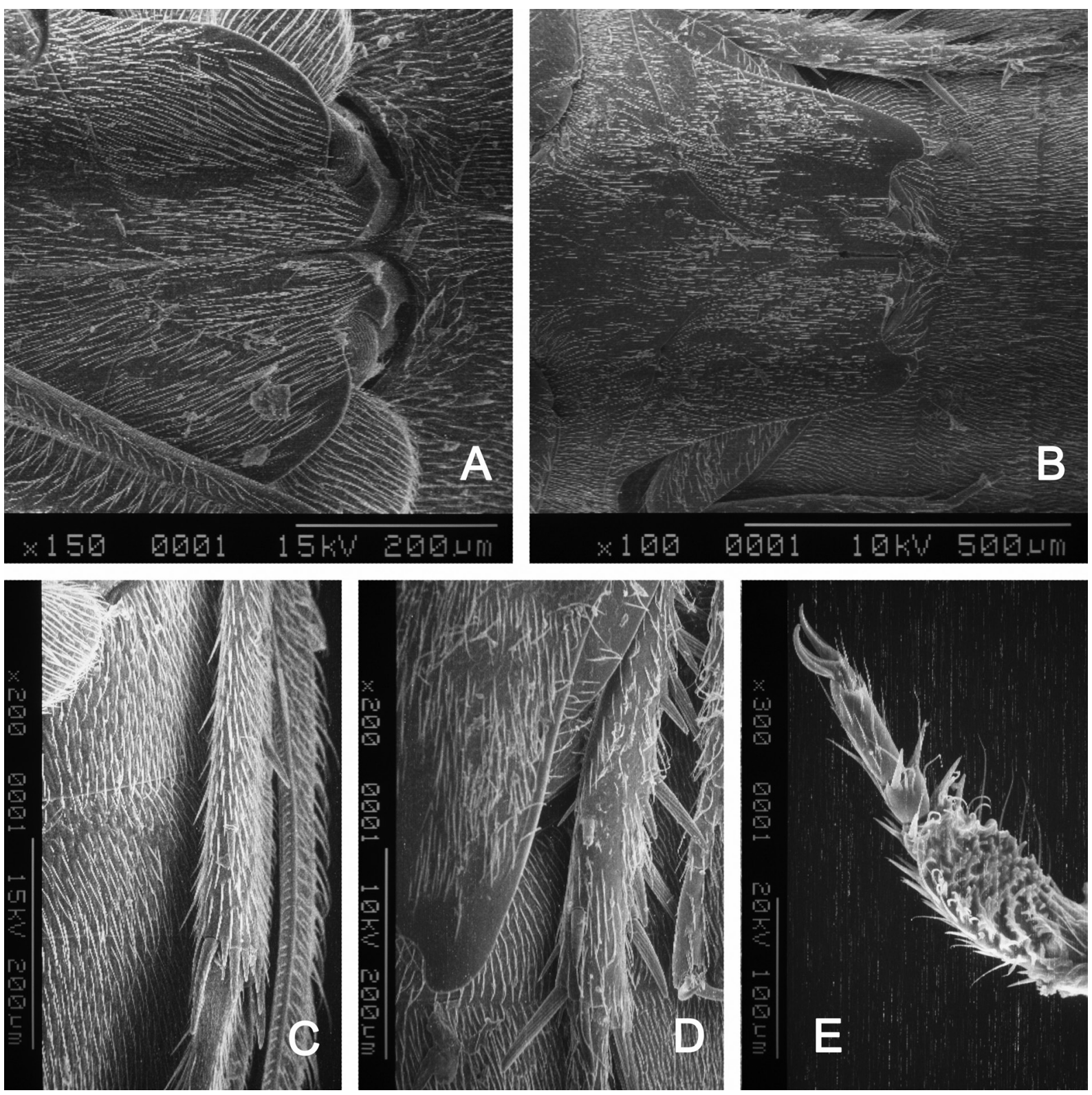

Fig. 3. Metacoxal plates (A-B), hind tibiae (C-D) and male protarsus (E). A, C. Acontosceles chujoi Yoshitomi \& Satô, 2005. B, D. Mexico taiwanus (Satô, 1994). E. Pseudeucinetus zygops Heller, 1921. 
3. Antennae 7-segmented; antennal groove on gena absent; Neotropical Region

.Martinius Spilman, 1959

- Antennae 11-segmented; antennal groove on gena present; Neotropical and Oriental Regions..

Mexico Spilman, 1972

Genus Acontosceles Champion, 1924

Acontosceles Champion, 1924a: 27 (type species: Acontosceles hydroporoides Champion, 1924).

\section{Diagnosis}

Body elongate. Gena wide; antennal groove absent. Antennae slender, relatively long, 11-segmented; antennal insertions situated near eyes. Legs long and slender; tarsal formula 4-5-5.

\section{Remarks}

This genus was subdivided into two species groups by Pütz (2008) mainly based on the male genital characters. However, the points differentiating the two groups are obvious and quantitative features (see also Yoshitomi \& Putra 2011), and so the species-group concept needs to be revised.

\section{Biological notes}

The habitat of this genus (Fig. 4A) is freshwater environments, i.e., waterfalls (type locality of A. chujoi Yoshitomi \& Satô, 2005), rivers and streams. The adults are found on wet rocks or actively flying. The larval stages are unknown.

\section{Key to the males of the species of Acontosceles}

1. Basal piece distinctly curved ventrally, expanded in basal part; parameres long and curved ventrally, minutely serrate on dorso-lateral margins in some species; body shape elongate to oblong-oval; legs relatively long; Japan to India, Indonesia 2 (A. hydroporoides species group)

- Basal piece slightly curved ventrally, not expanded in basal part; parameres short and almost straight, lacking serrae on dorso-lateral margins; body shape oblong-oval; legs relatively short; Indochina to Himalayas 9 (A. quatuordecimmaculosus species group)

2. Aedeagus distinctly curved (about $90-100^{\circ}$ ) ventrally in basal piece.............................................. 5

- Aedeagus gently curved (about $120^{\circ}$ ) ventrally in basal piece........................................................ 3

3. Lateral lobes serrate on dorso-lateral margins

- Lateral lobes lacking serrae on dorso-lateral margins A. hydroporoides Champion, 1924

4. Basal piece slightly expanded in basal part; Indochina A. chujoi Yoshitomi \& Satô, 2005

- Basal piece robust, expanded in basal part; Japan and Taiwan.. A. yorioi Satô, 1966

5. Lateral lobes serrate on dorso-lateral margins

- Lateral lobes lacking serrae on dorso-lateral margins; Philippines A. negrosensis Pütz, 2008

6. Basal piece robust, expanded in basal part 7

- Basal piece slightly expanded in basal part; Borneo A. borneensis sp. nov.

7. Basal piece curved in middle part. 8

- Basal piece curved in caudal part; Philippines A. jaechi Pütz, 2008 
8. Lateral lobes shorter; Indonesia...

A. javanicus Yoshitomi \& Putra, 2011

- Lateral lobes longer; Philippines A. tagalog Spilman, 1959

9. Apex of lateral lobes wide and truncate, with small denticles on lateral margins ........................... 10

- Apex of lateral lobes pointed, lacking denticles .............................................................................

10. Lateral margins of lateral lobes gently arcuate in dorsal view; Nepal.......A. siwalikensis Pütz, 2008

- Lateral margins of lateral lobes straight in dorsal view; Thailand and Laos........ A. zetteli Pütz, 2008

11. Basal piece relatively long; lateral lobes slightly curved in apical parts; Myanmar

A. quatuordecimmaculosus Pütz, 2008

- Basal piece relatively short; lateral lobes curved ventrally in apical parts; China

A. yunnanensis Pütz, 2008
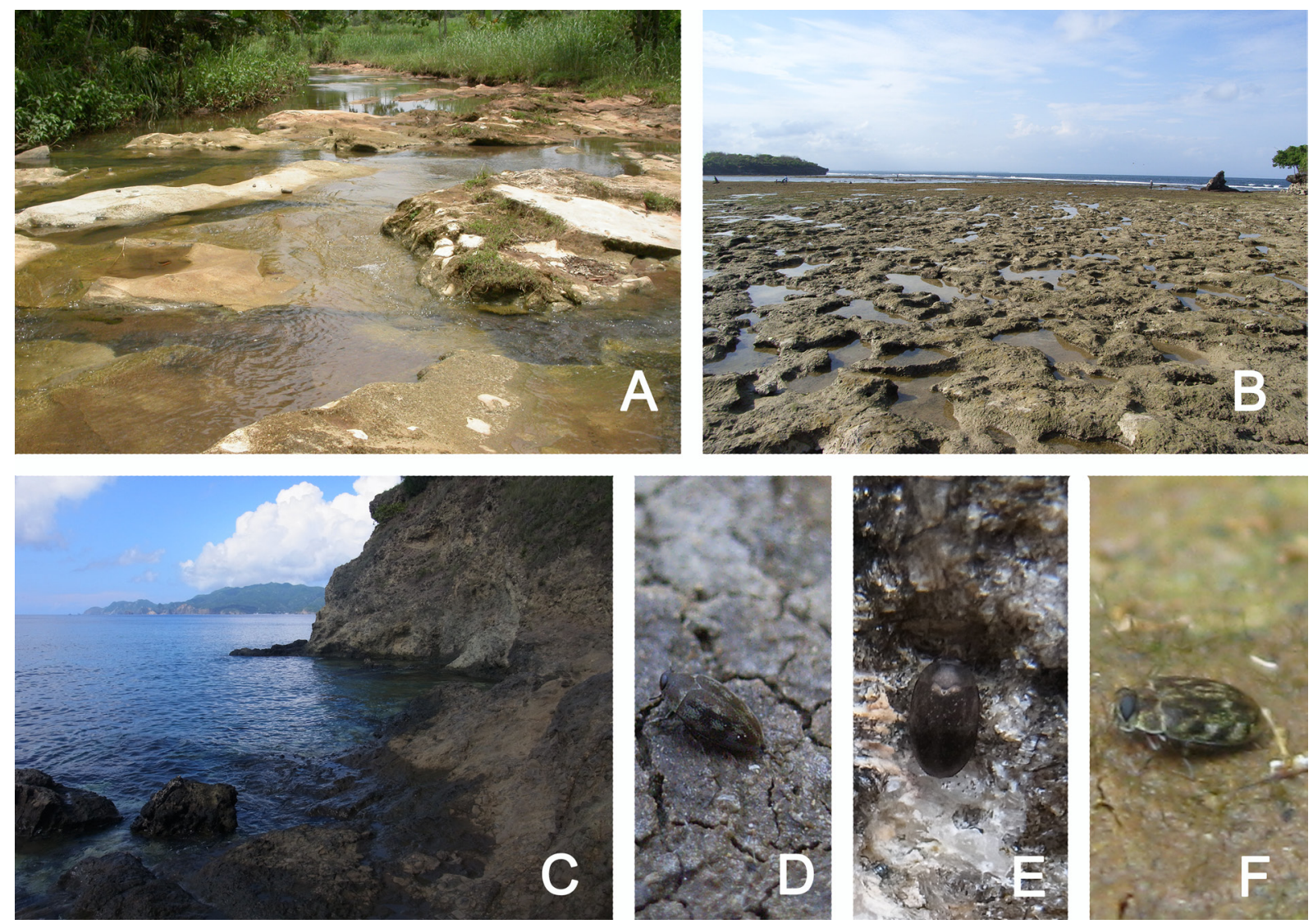

Fig. 4. Habitats (A-C) and living adults (D-F) of Asian Thaumastodinae Champion, 1924. A. Dondong River, Pengkol, Yogyakarta special Region, Java, Indonesia (type locality of Acontosceles javanicus Yoshitomi \& Putra, 2011 (F) and Pseudeucinetus javanicus Yoshitomi \& Putra, 2010 (D)). B. Nusa Dua, Bali, Indonesia (type locality of Mexico baliensis sp. nov.). C. Hirashima, Ogasawara, Japan (type locality of Mexico ogasawaraensis sp. nov.). D. Type locality of Pseudeucinetus javanicus Yoshitomi \& Putra, 2010. E. Mexico masamii (Satô, 1994) in Shikinejima, Izu Islands. F. Type locality of Acontosceles javanicus Yoshitomi \& Putra, 2011. 


\section{Acontosceles borneensis sp. nov. \\ urn:Isid:zoobank.org:act:2582F411-8790-4937-B6A0-248899FD9208 \\ Figs 5A, 6}

\section{Etymology}

This species is named after its type locality.

\section{Material examined}

\section{Holotype}

MALAYSIA • đ̃; "SARAWAK: Nanga Pelagus 7-14. VIII. “58”; “T. C. Maa Collector BISHOP”; BPBM.

\section{Paratypes}

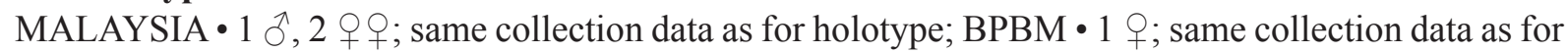
preceding; EUMJ • 2 + $O$; "BORNEO: SARAWAK Merirai Valley nr Kapit, 30-300m, 1-6. VII. 58”; "T. C. Maa Collector BISHOP Mus."; BPBM • 1 O; "BORNEO: SARAWAK Bau, Lake Area 29-30. VIII. 1958”; “T. C. Maa Collector BISHOP”; BPBM.

\section{Description}

\section{Male}

BoDy. Oblong, subparallel-sided, slightly convex dorsally, weakly shiny, closely covered with suberect silver setae. Coloration of body blackish brown, but mouthparts and legs yellowish brown; elytra with obscure silver spots consisting of erect setae.

HEAD. Moderate in size; frons and clypeus closely covered with erect, long silver setae; clypeus with straight anterior margin. Eyes large, prominent dorso-laterally.

ANTENNAE. Reaching about proximal half of pronotum.

Pronotum. Widest at basal third, densely bearing short yellowish setae and minute scale-like setae; PW/PL 2.25-2.50 (2.34). Scutellum small, subtriangular.

ELYTRA. Oblong, subparallel-sided near base to apical fifth, densely covered with short yellowish setae and minute scale-like setae, projecting ventrally in apical part; EL/EW 1.59-1.80 (1.72); EL/ PL 4.174.63 (4.39); EW/PW 1.02-1.16 (1.10); TL/EW 1.97-2.22 (2.11).

AвDOMEn. Sternite VII (Fig. 6A) broad, gently arcuate along caudal margin, shallowly concave in median part, bearing about 20 long setae and three pairs of long and stout setae. Sternite VIII (Fig. 6B) membranous, bearing minute spines in apical parts. Sternite IX (Fig. 6C) moderately sclerotized, large, with small apical plates.

Aedeagus (Fig. 6D-E). Long, well sclerotized, strongly curved ventrally; basal piece oblong, expanded basally, evenly curved ventrally; lateral lobes long and slender, serrate on dorso-lateral margins, curved ventrally; median lobe long and slender, about 0.6 times as long as lateral lobe, gently curved ventrally; ML/BL 0.36; ML/LL 0.68 .

\section{Female}

Sexual dimorphism distinct in the following characteristics: 1) frons and clypeus covered with short yellowish setae; 2) apical part of elytra projecting ventro-apically; 3) sternite VII (Fig. 6F) rather pointed on caudal margin, bearing about 40 long setae. Urosternite (Fig. 6G) well sclerotized, with long and 
slender apodeme; lateral projections stout, bifid in apical parts. Ovipositor (Fig. 6H) well sclerotized; coxite sparsely punctuate, pointed at apices; approximate ratio of coxite and baculus $(n=1)$ of $1.0: 1.7$.

\section{Measurements}

Unsexed (n = 4): TL 2.17-2.25 (2.21) mm; PW 0.90-1.00 (0.96) mm; PL 0.40-0.42 (0.41) mm; EL 1.75-1.85 (1.80) mm; EW 1.00-1.10 (1.05) mm.

\section{Distribution}

Malaysia (Sarawak).

\section{Remarks}

This species belongs to the hydroporoides species group judging from characteristics of the male genitalia.
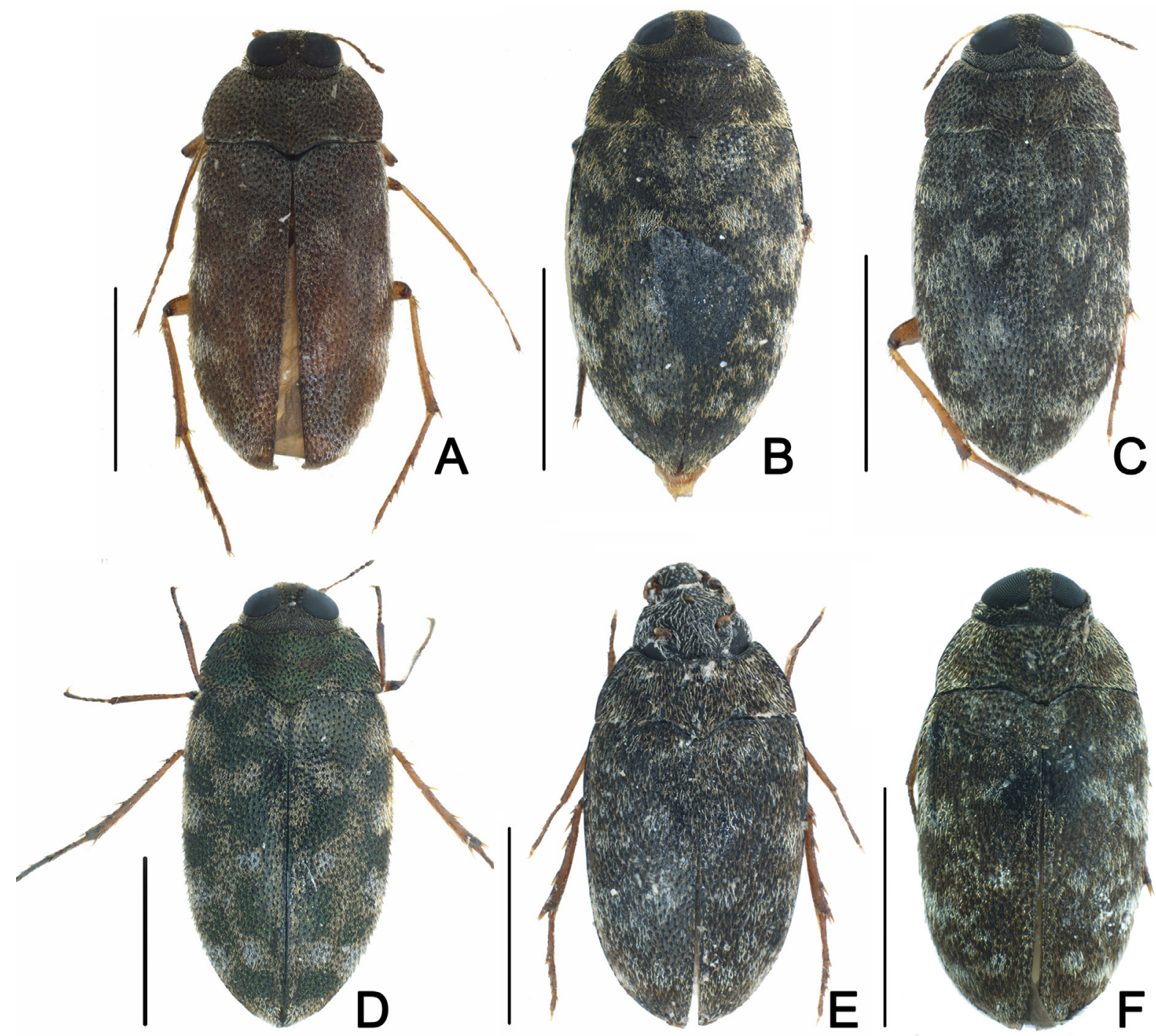

Fig. 5. Acontosceles spp. A. A. borneensis sp. nov., holotype (BPBM). B. A. yorioi Satô, 1966 (EUMJ). C. A. hydroporoides Champion, 1924 (NME). D. A. chujoi Yoshitomi \& Satô, 2005 (EUMJ). E. A. siwalikensis Pütz, 2008 (NME). F. A. zetteli Pütz, 2008 (BPBM). Scale bars: $1.0 \mathrm{~mm}$. 

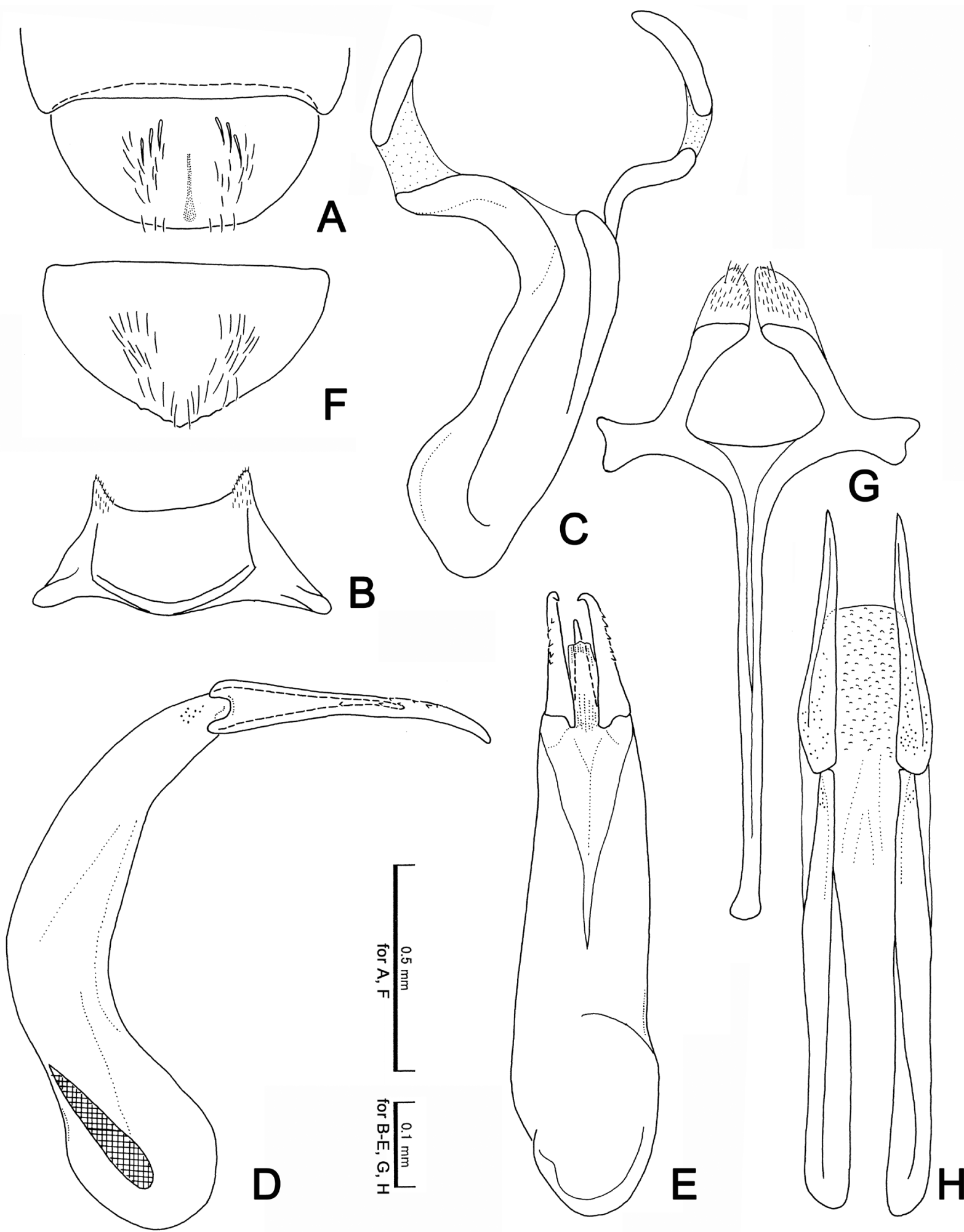

Fig. 6. Acontosceles borneensis sp. nov., male (A-E) and female $(\mathrm{F}-\mathrm{H})$ genitalia (holotype and paratype, BPBM). A, F. Sternite VII. B. Sternite VIII. C. Sternite IX. D. Aedeagus, left lateral view. E. Aedeagus, ventral view. G. Urosternite. H. Ovipositor. 
Acontosceles chujoi Yoshitomi \& Satô, 2005

Fig. 5D

Acontosceles chujoi Yoshitomi \& Satô, 2005: 35.

\section{Material examined}

LAOS • 12 ex.; "[LA8] Nam Xan, near Ban Nahoung, Xieng Khouang Prov., Laos, 1909.134" N, $103^{\circ} 43.037^{\prime \prime}$ E, 1453 m, 25. V. 2013 H. Yoshitomi leg."; EUMJ • 23 ex.; "[LA23] 2km W of Nam Chat, Laos, 19²90137" N, 102424900" E, ca 814 m, 22. IV. 2018, H. Yoshitomi leg.”; EUMJ.

VIETNAM • 5 ex.; “Tam Dao (950-1,050m) Vinh Phu Prov., Vietnam, 19. V. 1995 M. Sato leg.”; EUMJ • 11 ex.; "[VN6] Ban Khoang, Lao Cai Prov., Vietnam, N22 24.423 E103 47.309, ca 1284 m, 22. VI. 2012, H. Yoshitomi leg."; EUMJ.

\section{Distribution}

Laos, Vietnam (new record).

Acontosceles yorioi Satô, 1966

Fig. 5B

Acontosceles yorioi Satô, 1966: 60.

Acontosceles hydroporoides - Satô 1965: 123 [misidentification]. — Spangler et al. 2001: 152 [Taiwan, error].

Acontosceles yorioi - Yoshitomi \& Satô 2005: 36.

\section{Material examined}

JAPAN • 3 ex.; "Sate-gawa Kunigami, Okinawa 18-VI-2006 K. Takahashi leg."; EUMJ • 3 ex.; "Hijikawa, Kunigami, Okinawa, Ryukyus 15-VI-2003 K. Takahashi leg.”; EUMJ.

TAIWAN • 1 ex.; "Taiwan Nantou Chunyang VI/11--VII/9/2002 C. S. Lin \& W. T. Yang Malaise trap (KCN)"; "NMNS ENT 5240-73"; NMNS • 1 ex.; "Taiwan Nantou Chunyang V/7--VI/1/2002 C. S. Lin \& W. T. Yang Malaise trap (KCN)"; "NMNS ENT 5237-3502"; NMNS • 1 ex.; "Taiwan Nantou Chunyang V/11-VII/3/2004 C. S. Lin \& W. T. Yang Malaise trap (KCN)"; "NMNS ENT 5249-6740"; NMNS • 1 ex.; "Taiwan Pingtung Manchou Lite No: 169 Hsiang Rd. 3.8km IV/19--V/1/2009 M. L. Jeng \& T. J. Chen Malaise trap"; NMNS.

\section{Distribution}

Japan: Ryukyu Islands (Okinawa-jima, Ishigaki-jima, Iriomote-jima); Taiwan.

\section{Acontosceles siwalikensis Pütz, 2008}

Figs 5E, 7

Acontosceles siwalikensis Pütz, 2008: 314.

\section{Material examined}

NEPAL • 1 J , 5 ex.; "NEPAL, Prov. Bheri Distr. Surkhet, 20km S Surkhet, Bheri-River 600m NN, 03. VI. 1995 leg. M. Hartmann"; NME 1 § , 1 o; same collection data as for preceding; EUMJ. 


\section{Redescription}

For a detailed description of the external features, see the original description (Pütz 2008). PW / PL 2.63; EL/EW 1.58; EL/PL 4.70; EW/PW 1.13; TL/EW 1.92.

\section{Male}

Sternite VII (Fig. 7A) gently arcuate on caudal margin, bearing about 30 long setae in median part. Sternite VIII (Fig. 7B) membranous. Sternite IX (Fig. 7C) slightly sclerotized, with long apical plates bifid in apical parts. Aedeagus (Fig. 7D-F) relatively short, well sclerotized, slightly curved ventrally; basal piece oblong, subparallel-sided; lateral lobes short and broad, arcuate on lateral margins, closely punctuate, with small projections in lateral parts of apices; median lobe slender, about 0.8 times as long as lateral lobe, slightly curved ventrally; ML/BL 0.40; ML/LL 0.80.

\section{Female}

Sexual dimorphism slight. Sternite VII (Fig. 7G) arcuate on caudal margin, bearing about 40 long setae. Urosternite (Fig. 7H) well sclerotized, with long and slender apodeme; lateral projections short, projecting antero-laterally. Ovipositor (Fig. 7I) well sclerotized; coxite closely punctuate, pointed at apices; approximate ratio of coxite and baculus $(\mathrm{n}=1) 1.0: 1.8$.

\section{Measurements}

Male ( $\mathrm{n}=1)$ : TL 2.28 mm; PW 1.05 mm; PL 0.40 mm; EL 1.88 mm; EW 1.19 mm.

\section{Distribution}

Nepal.

\section{Acontosceles zetteli Pütz, 2008}

Figs 5F, 8

Acontosceles zetteli Pütz, 2008: 317.

\section{Material examined}

LAOS • 1 đ ; "LAOS: Vientiane Prov. Ban Van Eue 15. XII. 1966”; "Native Collector BISHOP”; BPBM.

\section{Redescription}

Male

For a detailed description of the external features, see the original description (Pütz 2008). PW/ PL 2.83; EL/EW 1.48; EL/PL 4.93; EW/PW 1.18; TL/EW 1.78.

Sternite VII (Fig. 8A) arcuate on caudal margin, bearing about 20 long setae in median part. Sternite VIII (Fig. 8B) membranous. Sternite IX (Fig. 8C) slightly sclerotized, with long apical plates bifid in apical parts. Aedeagus (Fig. 8D-F) short, well sclerotized, slightly curved ventrally; basal piece oblong, subparallel-sided; lateral lobes short and broad, straight on lateral margins, closely punctuate, minutely projecting ventro-laterally at apices; median lobe slender, about 0.8 times as long as lateral lobe, slightly curved ventrally; ML/BL 0.34; ML/LL 0.82.

\section{Female}

Unknown.

\section{Measurements}

Male (n=1): TL 1.78 mm; PW 0.85 mm; PL 0.30 mm; EL 1.48 mm; EW 1.00 mm. 

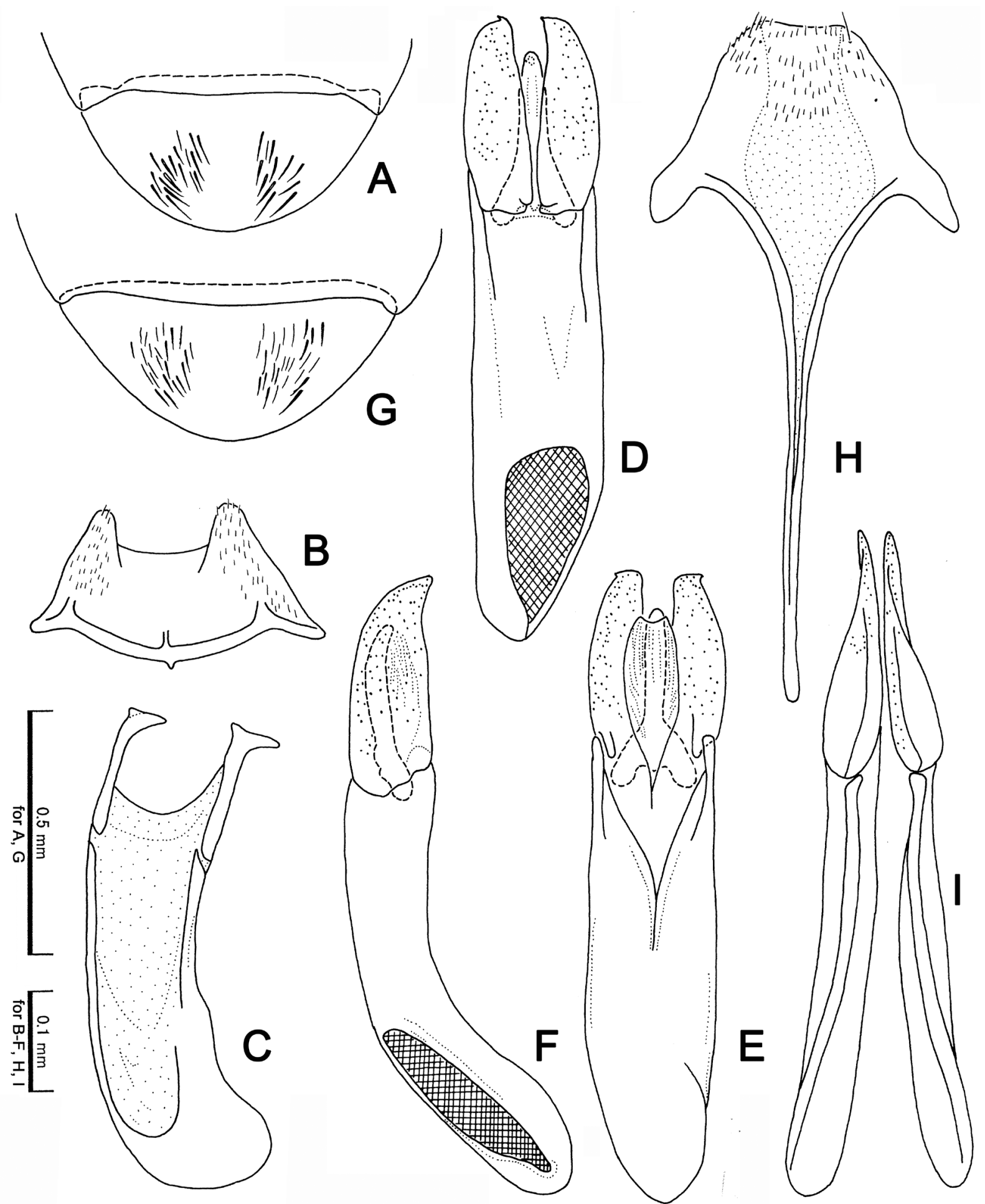

Fig. 7. Acontosceles siwalikensis Pütz, 2008, male (A-F) and female (G-I) genitalia (NME). A, G. Sternite VII. B. Sternite VIII. C. Sternite IX. D. Aedeagus, dorsal view. E. Aedeagus, ventral view. F. Aedeagus, left lateral view. H. Urosternite. I. Ovipositor. 


\section{Distribution}

Thailand, Laos (new record).

Genus Pseudeucinetus Heller, 1921

Pseudeucinetus Heller, 1921: 155 (type species: Pseudeucinetus zygops Heller, 1921).

Thaumastodus Champion, 1924a: 25 (type species: Thaumastodus fusiformis Champion, 1924; synonymized by Champion 1924b).

Pseudeucinetus - Satô 1994: 173. — Spangler 1995: 395.

\section{Diagnosis}

Body oblong. Gena wide; shallow antennal groove present. Frons (Fig. 2E-F) narrow, distinctly projecting anteriorly. Antennae stout and short, 11-segmented; antennal insertions situated near mandibles. Legs relatively short and stout; tarsal formula 4-4-4; male fore tarsi enlarged (Fig. 3E).

\section{Remarks}

This genus is easily distinguishable from other genera of the subfamily Thaumastodinae by the unique shape of the head: frons distinctly projecting anteriorly and narrow between the eyes.

\section{Biological notes}

The habitat of this genus (Fig. 4A) is freshwater environments, i.e., rivers and streams. The adults are found in the splash zone of wet rocks, and frequently actively flying. In Java, Indonesia, Pseudeucinetus
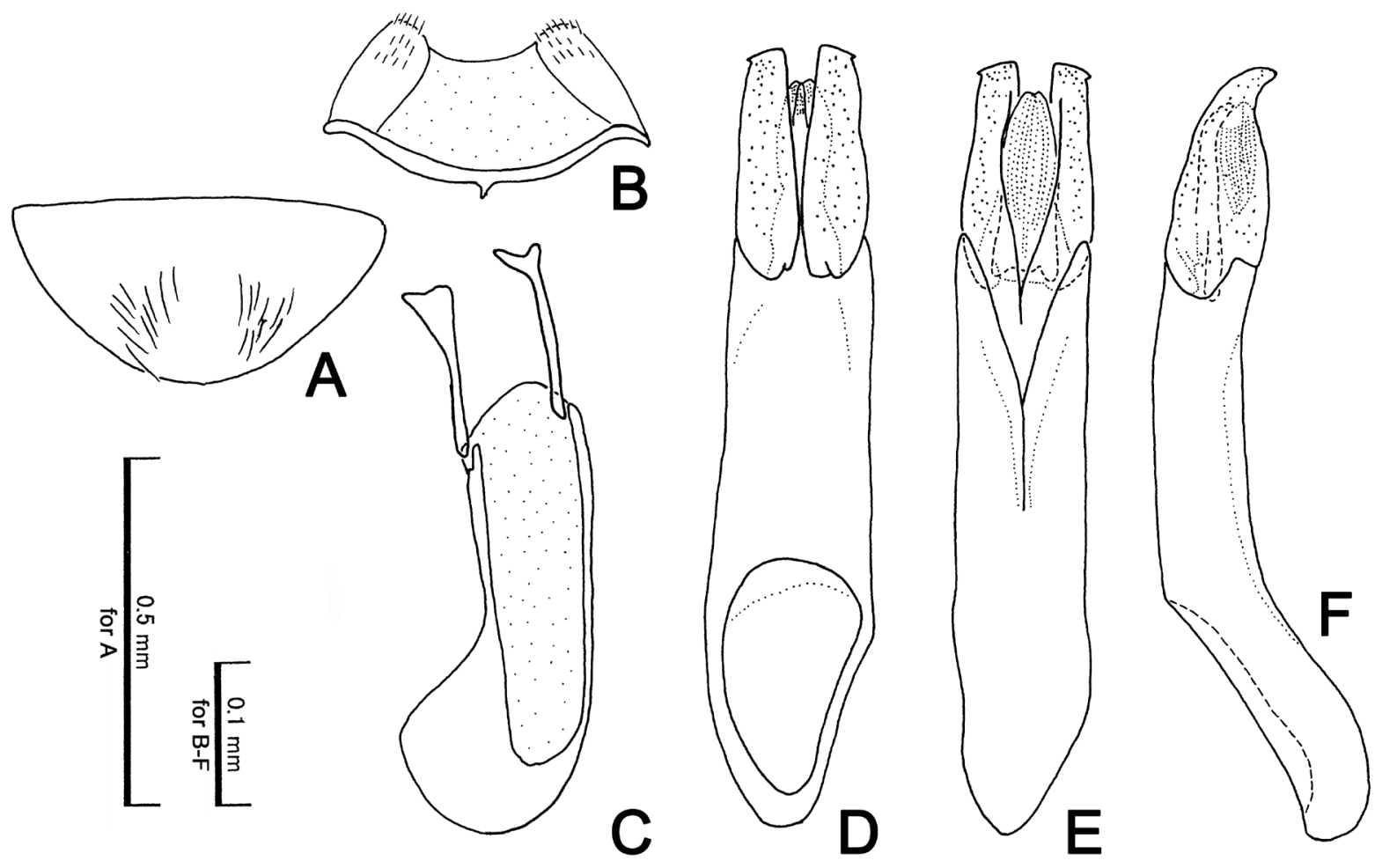

Fig. 8. Acontosceles zetteli Pütz, 2008, male genitalia (BPBM). A. Sternite VII. B. Sternite VIII. C. Sternite IX. D. Aedeagus, dorsal view. E. Aedeagus, ventral view. F. Aedeagus, left lateral view. 
javanicus and Acontosceles javanicus were collected in the same place (Yoshitomi \& Putra 2011). The adults were also collected by light trap. The larval stages are unknown.

Key to the males of the species of Pseudeucinetus (modified from Yoshitomi \& Putra 2010)

1. Lateral lobes with a pair of small projections on inner margins.................................................... 2

- Lateral lobes without any projections on inner margin ............................................................... 4

2. Subbasal inner projections of lateral lobes distinct and acute; basal piece short, about 0.5 times as long as lateral lobe

P. novabritannica Delève, 1973

- Subbasal inner projections of lateral lobes absent; basal piece long, about 0.7-0.8 times as long as lateral lobe

3. Subapical inner projections of lateral lobes small and obvious

P. papuanus sp. nov.

- Subapical inner projections of lateral lobes large and distinct

P. solomonicus Yoshitomi \& Putra, 2010

4. Apex of median lobe of aedeagus acuminate in dorsal or ventral view 5

- Apex of median lobe of aedeagus nipple-like in dorsal or ventral view .. P. spilmani Spangler, 1995

5. Median lobe strongly pointed at apex, straight on lateral margins; basal piece gently curved dorsally P. zygops Heller, 1921

- Median lobe weakly pointed at apex, arcuate on lateral margins; basal piece strongly curved dorsally

6. Apices of lateral lobes straight, acute; median lobe widest at the middle.....P. uenoi Spangler, 1995

- Apices of lateral lobes obtuse; median lobe widest at basal part

P. javanicus Yoshitomi \& Putra, 2010

\section{Pseudeucinetus papuanus sp. nov. \\ urn:1sid:zoobank.org:act:978D5D6D-8D48-425D-AB1B-0536A2E10753}

Figs 9A, 10

\section{Etymology}

This species is named after its type locality.

\section{Material examined}

\section{Holotype}

PAPUA NEW GUINEA • $\widehat{\text { O }}$; “NEW GUINEA NETH. Waris, S. of Hollandia, 450-500m VIII-I-2-1959”;

"T. C. Maa Collector BISHOP”; "At Light”; BPBM.

\section{Description}

\section{Male}

Body. Oval, slightly convex dorsally, shiny, closely covered with suberect silver setae. Coloration of body black; antennae and legs blackish brown.

HeAD. Moderate in size; clypeus with straight anterior margin. Eyes large; distance between eyes about 3 eye facets.

AntenNAE. Short, reaching about anterior third of pronotum. 
Pronotum. Widest at base; lateral margins straight; posterior margin gently bisinuate; PW/PL 2.33. Scutellum small, square.

ELYTRA. Oblong, widest at basal third; EL/EW 1.43; EL/PL 4.00; EW/PW 1.20; TL/EW 1.79. Fore tarsomere I largely expanded, longer than remaining fore tarsomeres combined.

AвDOMEn. Sternite VII (Fig. 10A) with three pairs of anterior extra setae (a) and two pairs of lateral extra setae (b). Sternite IX (Fig. 10B) moderately sclerotized, with long and pointed apical plates.
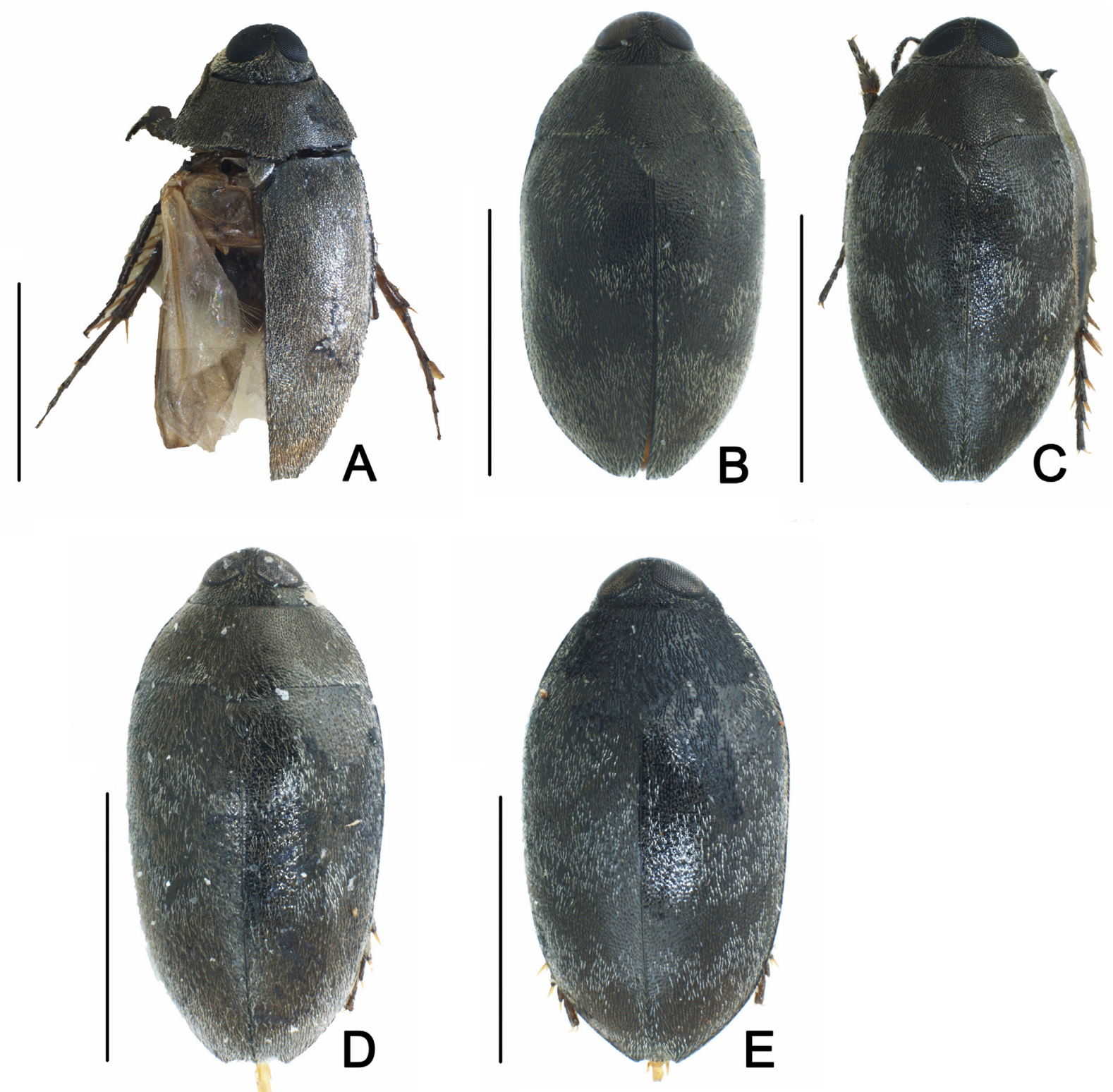

Fig. 9. Pseudeucinetus spp. A. P. papuanus sp. nov., holotype (BPBM). B. P. uenoi Spangler, 1995 (EUMJ). C. P. javanicus Yoshitomi \& Putra, 2010, paratype (EUMJ). D. P. solomonicus Yoshitomi \& Putra, 2010, paratype (EUMJ). E. P. zygops Heller, 1921 (EUMJ). Scale bars: $1.0 \mathrm{~mm}$. 
Aedeagus (Fig. 10C-D). Long, well sclerotized; basal piece oblong, subparallel-sided; lateral lobes long, about 1.4 times as long as basal piece, straight on lateral margins, with a pair of obtuse subapical inner projections on apical fifth; median lobe long, about 0.9 times as long as lateral lobes, nipple-like at apex; ML/BL 1.29; ML/LL 0.89.

\section{Female}

Unknown.
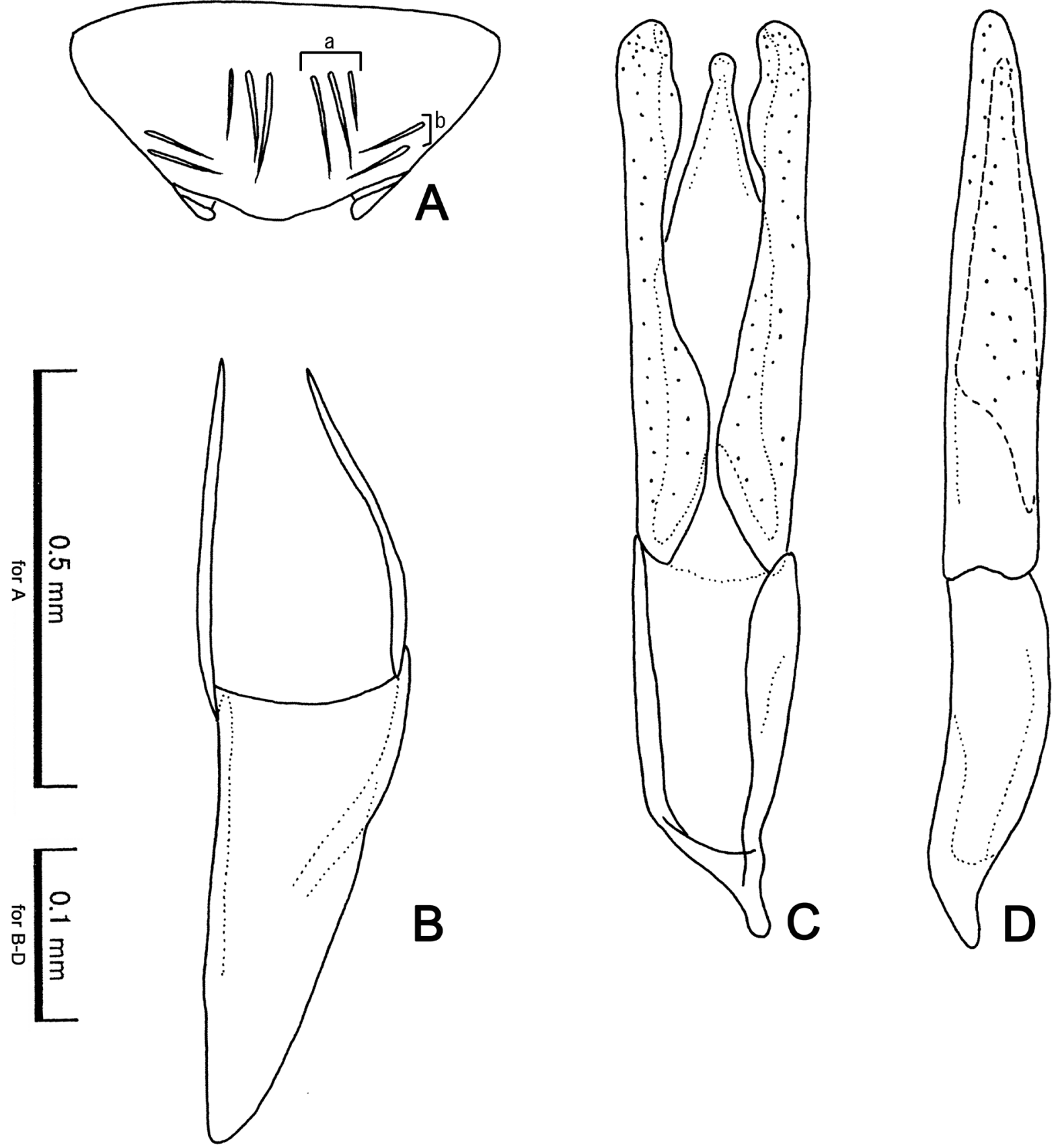

Fig. 10. Pseudeucinetus papuanus sp. nov., male genitalia, holotype, BPBM. A. Sternite VII. B. Sternite IX. C. Aedeagus, ventral view. D. Aedeagus, right lateral view. 


\section{Measurements}

Male ( $\mathrm{n}=1)$ : TL $2.15 \mathrm{~mm}$; PW $1.00 \mathrm{~mm}$; PL $0.43 \mathrm{~mm}$; EL $1.72 \mathrm{~mm}$; EW $1.20 \mathrm{~mm}$.

\section{Distribution}

Papua New Guinea.

\section{Remarks}

This species is related to Pseudeucinetus novabritannica from the Bismarck Archipelago and $P$. solomonicus from the Solomon Islands, and differs from them in the following characteristics: 1) subapical inner projection of lateral lobe obvious (large and distinct in P. solomonicus); 2) subbasal inner projection of lateral lobe absent (present in $P$. novabritannica); and 3) basal piece long, about 0.7 times as long as lateral lobe (about 0.5 in P. novabritannica, about 0.8 in P. solomonicus).

\section{Pseudeucinetus javanicus Yoshitomi \& Putra, 2010}

Figs 4A, D, 9C

Pseudeucinetus javanicus Yoshitomi \& Putra, 2010: 144.

\section{Material examined}

INDONESIA • 1 ว̊ં; "INDONESIA: Lombok I: Aik Bukak 2. VII. 1978”; “J. T. Medler Coll. BISHOP Museum Acc. \#1979. 483"; BPBM.

\section{Distribution}

Indonesia (Java, Lombok).

\section{Remarks}

This is the first record of this species from Lombok Island.

Pseudeucinetus zygops Heller, 1921

Fig. 9E

Pseudeucinetus zygops Heller, 1921: 156.

Thaumastodus fusiformis Champion, 1924a: 27 (synonymized by Champion 1924b).

Pseudeucinetus zygops - Satô 1994: 173. — Spangler 1995: 401. — Yoshitomi 2004: 420.

\section{Material examined}

INDONESIA • 1 ふ̋; "INDONESIA Southwest Sulawesi Aele 6-8. II. 2003 (LT) S. Hori leg.”; EUMJ.

MALAYSIA • 1 đ̋; "MALAYA Selangor Connaught Bridge 14. III. 1958"; "T. C. Maa Collector BISHOP 108”; BPBM.

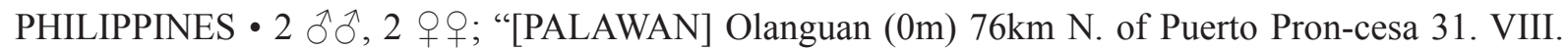
1985 M. Sakai leg."; "attracted to mercury lamp"; EUMJ • 3 ठิ but "26. VIII. 1985"; EUMJ • 1 क; "[PALAWAN] Trident Mine, 500m foot of Victoria Peak nr. Narra 4.

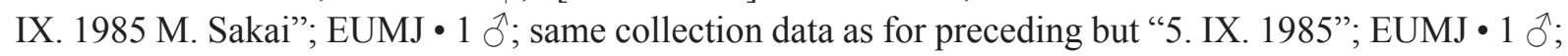
“[PALAWAN] Olanguan (0-50m) between Puerto Princesa \& Roxas 1. IX. 1985 M. Sakai”; EUMJ. 


\section{Distribution}

India, Indonesia (Sulawesi), Malaysian Peninsula, Bismarck Archipelago (New Ireland), the Philippines (Balabac, Palawan, Mindanao, Negros).

\section{Pseudeucinetus uenoi Spangler, 1995}

Fig. 9B

Pseudeucinetus uenoi Spangler, 1995: 396.

\section{Material examined}

MALAYSIA • 1 đ̊; "Miri Sarawak 11-XII-1968 M. Satô leg."; EUMJ • 1 đ̊; "MALAYSIA Mamut Ranau Sabah 27. Ii. 1995 [L. T.] YR. SAWADA leg."; EUMJ • 1 ð’; "Malaysia SABAH Kg. Sukau, Sandakan 15-16. XII. 2009 H. Takizawa"; ITBC • 1 क; "Malaysia SABAH Kg. Tikolod, Salt trail Tambunan 11. XI. 2009 H. Takizawa"; ITBC・ 1 क; "Malaysia SABAH Kg. Mansiang, Mengg-atal, Kota Kinabalu 21. XI. 2009 H. Takizawa"; ITBC.

\section{Distribution}

Malaysia (Sarawak, Sabah).

\section{Pseudeucinetus sp.}

\section{Material examined}

INDONESIA • 1 9; "IRIAN JAYA East of Serui Yapen Is. 28. VII. 1996 N. Ohbayashi”; EUMJ.

BRAZIL • 1 q; “BRAZIL: Cabo Frio 1m 20-21. XI. 1970”; “T. C. Maa Collector BISHOP”; BPBM.

\section{Remarks}

The single female specimen labelled as having been collected in Brazil is questionable, because this genus is otherwise known only from the Oriental Region.

\section{Genus Mexico Spilman, 1972}

Mexico Spilman, 1972: 113 (type species: Mexico litoralis Spilman, 1972, by original designation).

Babalimnichus Satô, 1994: 174 (type species: Babalimnichus taiwanus Satô, 1994: 174, by original designation). Syn. nov.

Mexico - Skelley 2005: 119.

Babalimnichus - Yoshitomi \& Satô 2001: 472 [larval description].

\section{Diagnosis}

Body oblong. Gena relatively narrow; shallow antennal groove present. Antennae stout and short, 11-segmented; antennal insertions situated near mandibles. Legs relatively short and stout; tarsal formula 4-4-4.

\section{Remarks}

As already mentioned by Skelley (2005), Babalimnichus Satô, 1994 cannot be separated from Mexico, and it should be treated as a junior synonym of the latter. 
The male genital structures are very peculiar, i.e., with very short lateral lobes with apical setae, longer median lobe and the presence of ventral plates (Fig. 1A).

\section{Biological notes}

The habitat of this genus (Fig. 4B-C) is rocky seashores. The adults (Fig. 4E) are found in the splash zone of wet rocks, actively flying when disturbed. The larval stage was described by Yoshitomi \& Satô (2001).

\section{Key to the males of the species of Asian Mexico*}

1. Lateral lobes long, exceeding proximal half of median lobe, with very short apical setae; Papua New Guinea... M. papuanus sp. nov.

- Lateral lobes short, reaching about proximal third of median lobe, with long apical setae..... 2

2. Ventral plates almost of same proportion on right and left. 4

- Apical part of left ventral plates distinctly curved interiorly..... 3

3. Left ventral plates with thumb-like projection on inner margin of apex; median lobe rather slender; Taiwan and Japan, Yonaguni-jima

M. taiwanus Satô, 1994 comb. nov.

- Left ventral plates long and curved interiorly in apical part, without thumb-like projection; median lobe wide, expanded in apical quarter; Japan, Honshu to Ishigakijima. M. masamii (Satô, 1994) comb. nov.

4. Apical part of ventral plates separated from median lobe; Palau M. palauensis sp. nov.

- Apical part of ventral plates connected with median lobe 5

5. Apex of median lobe nipple-like; Borneo M. borneensis sp. nov.

- Apex of median lobe simply pointed. 6

6. Lateral lobe robust, with 2-3 apical setae; Bali.

M. baliensis sp. nov.

- Lateral lobe slender, with 4 apical setae; Ogasawara Islands M. ogasawaraensis sp. nov.

${ }^{*}$ Mexico splendens (Hernando \& Ribera, 2003) comb. nov. is omitted, because this species is only known from a female specimen.

\section{Mexico ogasawaraensis sp. nov. urn:lsid:zoobank.org:act:8B1989C3-5D1B-4E9C-A87F-0ED19524F6D4}

Figs $4 \mathrm{C}, 11 \mathrm{C}, 12$

\section{Etymology}

This species is named after its type locality.

\section{Material examined}

\section{Holotype}

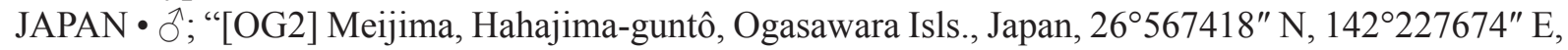
23. IX. 2012, H. Yoshitomi leg.”; EUMJ.

\section{Paratypes}

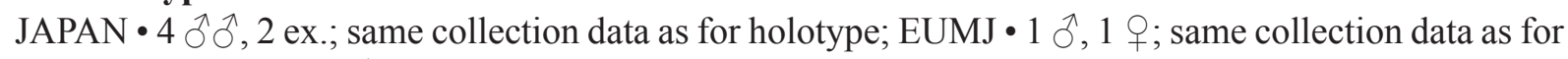
preceding; NSMT • 1 O , 1 क ; same collection data as for preceding; NMW • 1 क ; "[OG5] Minamizaki, Hahajima, Ogasawara Isls., Japan, 26³7.491" N, 142¹0.600" E, 25. IX. 2012, H. Yoshitomi leg."; 

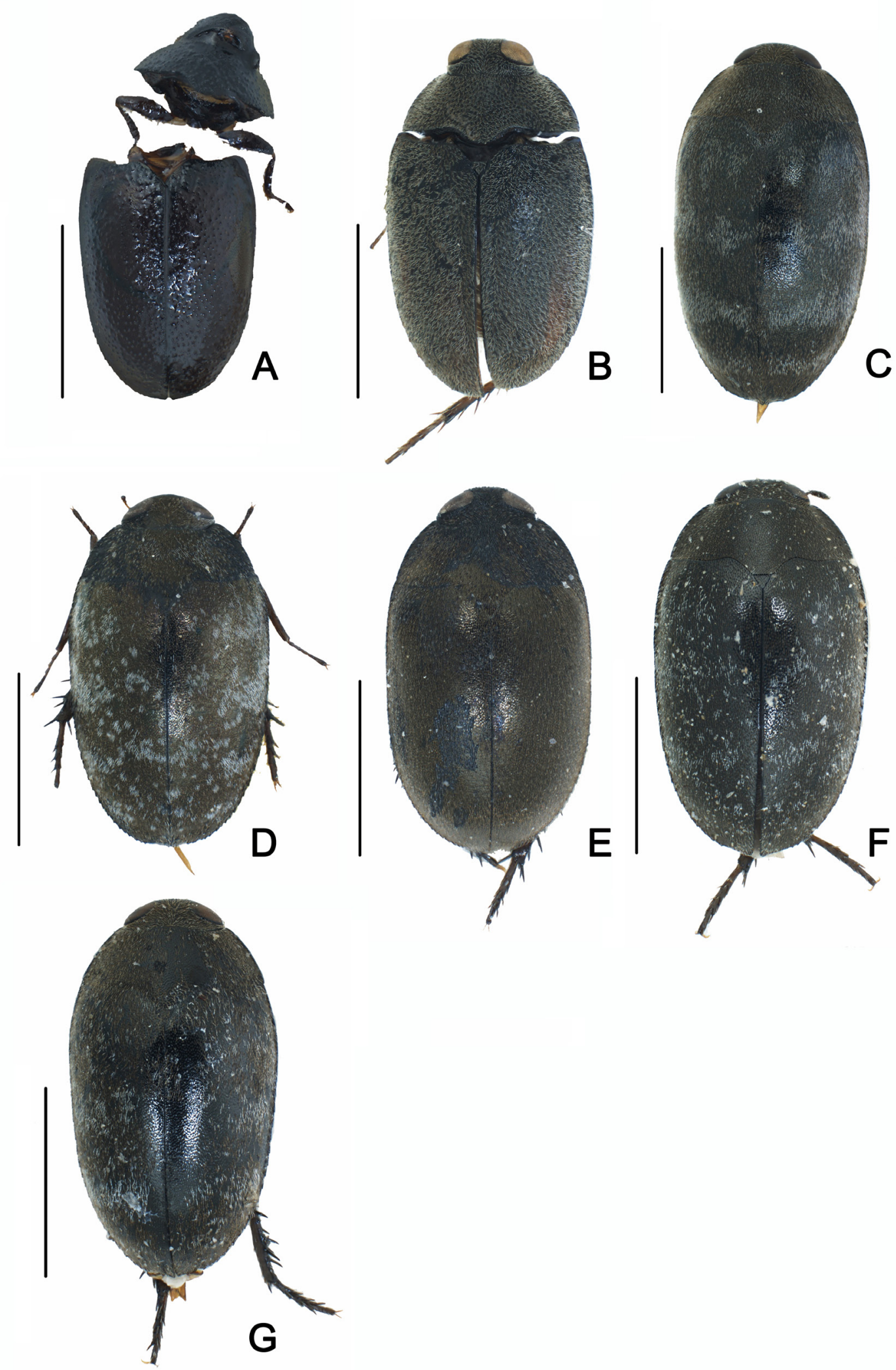

Fig. 11. Species of Mexico Spilman, 1972. A. M. borneensis sp. nov., holotype (BPBM). B. M. papuanus sp. nov., holotype (BPBM). C. M. ogasawaraensis sp. nov., holotype (EUMJ). D. M. baliensis sp. nov., holotype (EUMJ). E. M. palauensis sp. nov., holotype (EUMJ). F. M. masamii (Satô, 1994) (EUMJ). G. M. taiwanus (Satô, 1994), paratype (EUMJ). Scale bars: $1.0 \mathrm{~mm}$. 


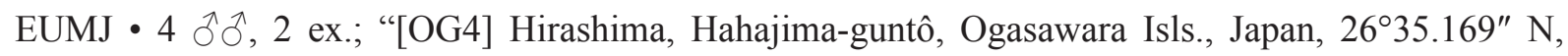
$142^{\circ} 09.177 "$ E, 24. IX. 2012, H. Yoshitomi leg.”; EUMJ.

\section{Description}

\section{Male}

BoDy. Oval, slightly convex dorsally, shiny, closely covered with suberect golden setae. Coloration of body black; elytra with indistinct and irregular silver spots consisting of erect setae.

HEAD. Closely and finely punctate, slightly convex between eyes; distance between eyes as long as an eye diameter in dorsal view.

ANTENNAE. Short, reaching about anterior third of pronotum.

Pronotum. Closely punctate, gently arcuate on lateral margins; PW/PL 1.92-2.30 (2.09). Scutellum equilateral triangular, punctate as in pronotum.

ELYTRA. Oval, widest at base, gently tapered posteriorly; caudal third of lateral margins slightly and indistinctly serrate; EL/EW 1.40-1.54 (1.48); EL/PL 3.25-4.00 (3.58); EW/PW 1.12-1.20 (1.16); TL/EW 1.80-1.96 (1.89).

AвDOMEN. Sternite VII (Fig. 12A) bearing about 40 long setae on mesal part, pointed at postero-lateral corners, slightly projecting on median part of caudal margin. Sternite VIII (Fig. 12B) slightly sclerotized, small, Y-shaped. Sternite IX (Fig. 12C) moderately sclerotized, relatively wide, strongly curved in basal part, with long and pointed apical plates.

Aedeagus (Fig. 12D-G). Long and slender, well sclerotized; basal piece oval; lateral lobes short and slender, with three apical setae; median lobe long and slender, slightly expanded in apical fifth, pointed at apex, finely punctuate; ventral plates slender, reaching about apical fifth of median lobe, mostly fused to median lobe; ML/BL 2.94; ML/LL 2.42.

\section{Female}

Sexual dimorphism slight. Sternite VII (Fig. 12H) bearing about 30 long setae on mesal part, pointed but minutely concaved at postero-lateral corners, slightly projecting on median part of caudal margin. Urosternite (Fig. 12I) well sclerotized, T-shaped, with long and slender apodeme. Ovipositor (Fig. 12J) well sclerotized; coxite sparsely punctuate; apex of baculus bifid; approximate ratio of coxite and baculus $(\mathrm{n}=1) 1.0: 6.1$.

\section{Measurements}

Unsexed (n = 20): TL 2.10-2.65 (2.39) mm; PW 0.98-1.20 (1.09) mm; PL 0.45-0.60 (0.52) mm; EL 1.65-2.05 (1.86) mm; EW 1.10-1.40 (1.26) mm.

\section{Distribution}

Japan: Ogasawara Islands (Hahajima, Meijima, Hirashima).

\section{Remarks}

This species appears to be closely related to M. baliensis sp. nov. based on the shape of the aedeagus, but differs from it in the following characteristics: sternite IX broad (slender in M. baliensis sp. nov.), median lobe pointed at apex (somewhat obtuse in M. baliensis sp. nov.) and apical setae on lateral lobes long (short in M. baliensis sp. nov.). 


\section{Biological notes}

The type series was collected from the splash zone of wet rocks on a rocky seashore (Fig. 4C).

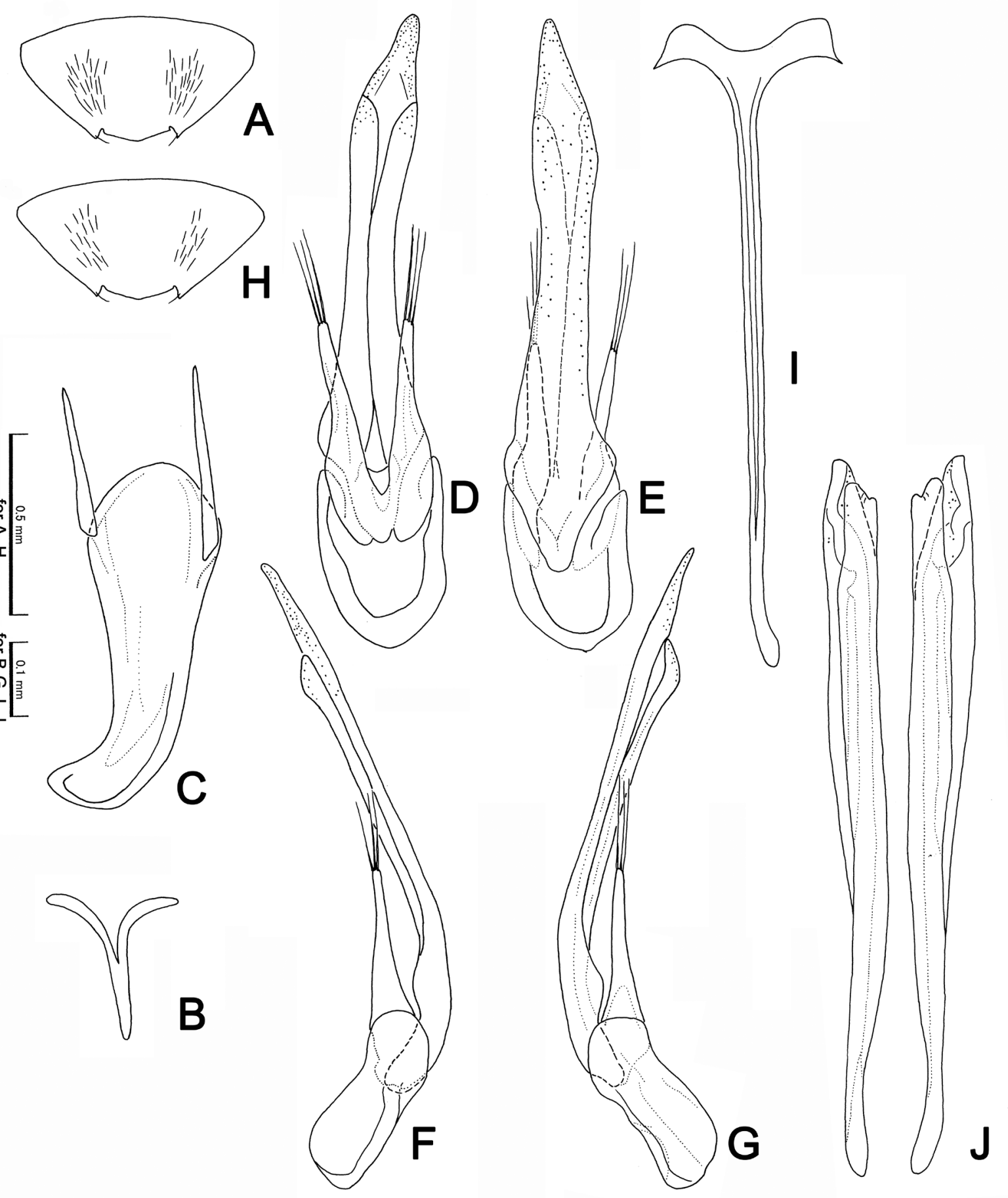

Fig. 12. Mexico ogasawaraensis sp. nov., male (A-G) and female (H-J) genitalia (paratypes, EUMJ). A, H. Sternite VII. B. Sternite VIII. C. Sternite IX. D. Aedeagus, ventral view. E. Aedeagus in dorsal view. F. Aedeagus in right lateral view. G. Aedeagus, left lateral view. I. Urosternite. J. Ovipositor. 
Mexico baliensis sp. nov. urn:1sid:zoobank.org:act:98D64DE9-6A33-4EBF-A7F9-26F9A7BA409E

Figs 4B, 11D, 13

\section{Etymology}

This species is named after its type locality.

\section{Material examined}

\section{Holotype}

INDONESIA • đ̊; "Bali Is. Indonesia Nusa Dua, Kuta South 16-II-2013 Kiyoshi ANDO leg.”; EUMJ.

\section{Paratypes}

INDONESIA 1 $1 \hat{\partial}, 3$ 우, 2 ex.; same collection data as for holotype; EUMJ • 3 ex.; "Nusa Dua, North Island 8 $8^{\circ} 7^{\prime} 52.72^{\prime \prime}$ S, 115¹4'9.31" E, Bali, INDONESIA 7-8. VIII. 2010 H. Yoshitomi leg."; EUMJ • 1 ex.; same collection data as for preceding; NMW 1 ex.; same collection data as for preceding; BPBM •

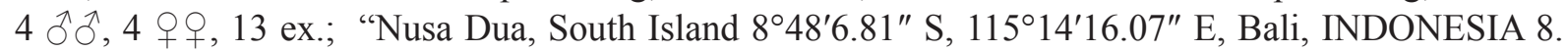
VIII. 2010 H. Yoshitomi leg."; 1 o on slide no HY 1141; EUMJ • 3 ex.; same collection data as for preceding; NMW • 3 ex.; same collection data as for preceding; BPBM.

\section{Description}

\section{Male}

BoDy. Oval, slightly convex dorsally, shiny, closely covered with suberect golden setae. Coloration of body black; elytra with small, irregular silver spots consisting of erect setae.

HEAD. Finely punctate, projecting anteriorly between eyes; distance between eyes about 0.8 times as long as eye diameter in dorsal view.

ANTENNAE. Very short, reaching about anterior quarter of pronotum.

Pronotum. Closely punctate, gently arcuate on lateral margins; PW/PL 1.75-2.55 (2.06). Scutellum square.

ELYTRA. Oval, widest at base, gently tapered posteriorly; caudal third of lateral margins serrate; EL/EW 1.32-1.43 (1.38); EL/PL 2.53-4.00 (3.25); EW/PW 1.09-1.20 (1.14); TL/EW 1.67-1.88 (1.81).

Abdomen. Sternite VII (Fig. 13A) with two pairs (inner and outer) of long and stout setae and two extra pairs of such setae, pointed at postero-lateral corners, slightly projecting on median part of caudal margin. Sternite VIII (Fig. 13B) slightly sclerotized, small, Y-shaped. Sternite IX (Fig. 13C) moderately sclerotized, slender, curved in basal part; apical plates long, truncate at apices.

Aedeagus (Fig. 13D-G). Long and slender; basal piece oval, subparallel-sided; lateral lobes short and robust, with 2-3 apical setae; median lobe long and slender, subparallel-sided near base to apex, finely punctuate, pointed at apex; ventral plates long and slender, reaching about apical tenth of median lobe, mostly fused to median lobe; ML/BL 2.26; ML/LL 2.72.

\section{Female}

Sexual dimorphism slight. Sternite VII (Fig. 13H) similar to that of male, but one pair, not two, of extra inner setae. Urosternite (Fig. 13I) well sclerotized, Y-shaped, with long and slender apodeme. Ovipositor (Fig. 13J) well sclerotized; coxite sparsely punctuate, rather pointed at apices; apex of baculus bifid; approximate ratio of coxite and baculus $(n=1) 1.0: 6.2$. 


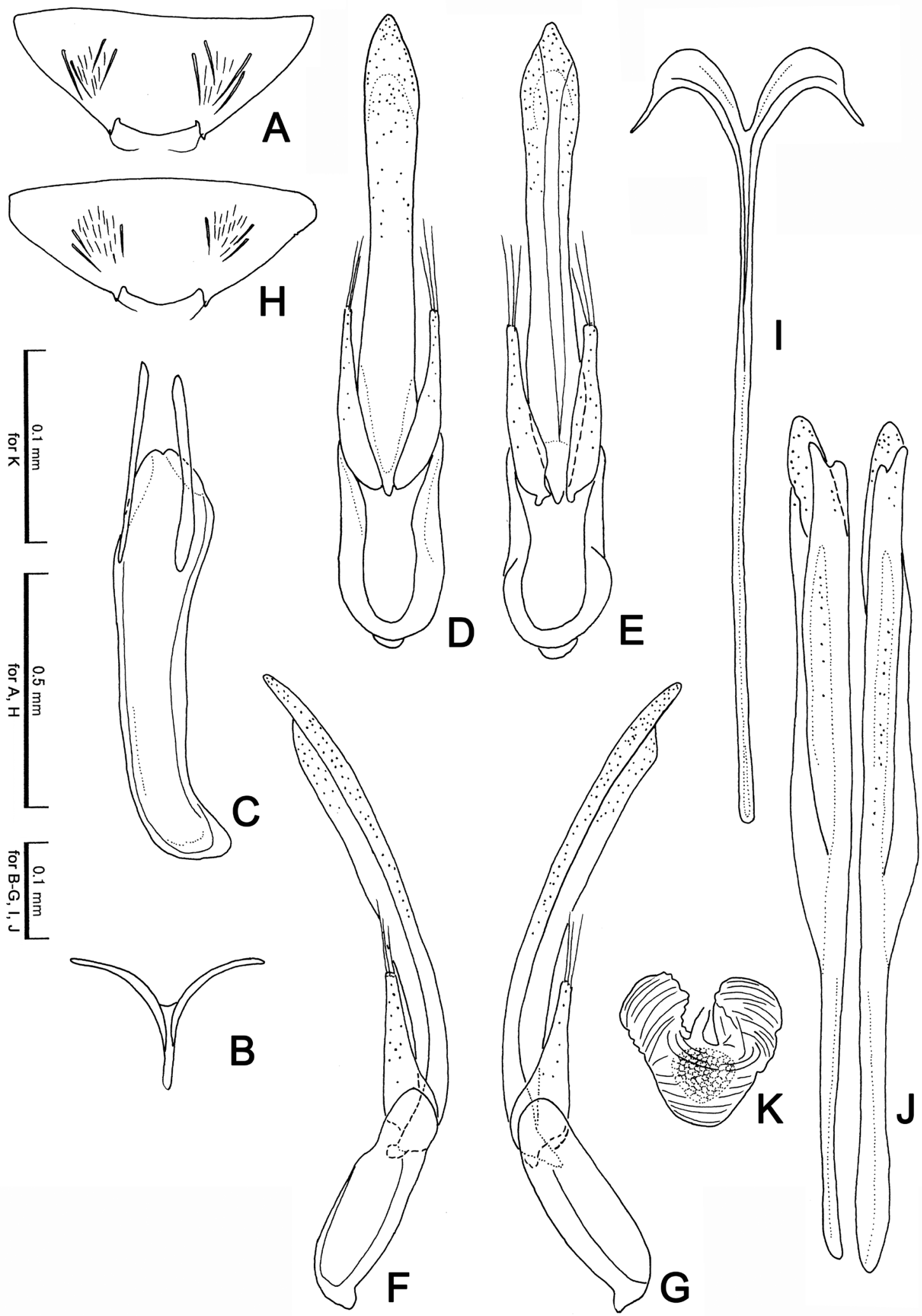

Fig. 13. Mexico baliensis sp. nov., male $(\mathrm{A}-\mathrm{G})$ and female $(\mathrm{H}-\mathrm{K})$ genitalia (paratypes, EUMJ). A, H. Sternite VII. B. Sternite VIII. C. Sternite IX. D. Aedeagus in dorsal view. E. Aedeagus, ventral view. F. Aedeagus in right lateral view. G. Aedeagus, left lateral view. I. Urosternite. J. Ovipositor. K. Spermatheca. 


\section{Measurements}

Unsexed $(\mathrm{n}=20)$ : TL 1.88-2.40 (2.19) mm; PW 0.95-1.13 (1.06) mm; PL 0.40-0.60 (0.52) mm; EL 1.48-1.80 (1.67) mm; EW 1.05-1.30 (1.21) mm.

\section{Distribution}

Indonesia (Bali Island).

\section{Remarks}

This species is similar to M. borneensis sp. nov. in the shape of the aedeagus, but differs from it in the following characteristics: median lobe obtuse at apex (pointed in M. borneensis sp. nov.); and apical setae on lateral lobes relatively short (long in M. borneensis sp. nov.).

\section{Biological notes}

The type series was collected from the surface of wet rocks on a seashore (Fig. 4B) together with three species of Laius Guérin-Méneville, 1830 (Melyridae: L. baliensis Yoshitomi, 2014, L. satoi Yoshitomi, 2008 and L. pankowi Wittmer, 1999) and Parathroscinus sp. (Limnichidae) (Yoshitomi 2008, 2014b).

$$
\begin{aligned}
& \text { Mexico papuanus sp. nov. } \\
& \text { urn:lsid:zoobank.org:act:DB69DE47-18E6-4FA0-8D94-A9A95470D78E }
\end{aligned}
$$

Figs 11B, 14

\section{Etymology}

This species is named after its type locality.

\section{Material examined}

\section{Holotype}

PAPUA NEW GUINEA • \} \text { ; "NEW GUINEA (NE) Dreikikir, Sepik Distr., 350m 25. VI. 1961”; "J. L. \& } M. Gressitt Collectors"; BPBM.

\section{Paratypes}

PAPUA NEW GUINEA • $1 \hat{\jmath}, 1$; ; same collection data as for holotype; BPBM $\bullet 1$; ; same collection data as for holotype but "23. VI. 1961"; BPBM • 1 क; same collection data as for holotype but "24. VI. 1961"; BPBM • 1 क; "NEW GUINEA: NETH. VOG ELKOP: Bomberi 700-900m, VI-9- "59”; "J. L. Gressitt Collector"; BPBM - 1 đ̊; "NE New Guinea Morabe Distr. 10km W Bulolo 780m, 5-25. VIII, 1967"; "Malaise tr. over stream"; "R. Straatman Collector BISHOP MUS.”; BPBM • 1 ð̊; "NE NEW GUINEA Akivitana Riv. 1550m, 10. I. 65"; "J. \& M. Sedlacek Collectors BISHOP MUSEUM"; BPBM • 1 §̊; "NEW GUINEA: NETH. Waris, S. of Hollandia, 450-500m VIII-1-2-1959"; "At Light"; "T. C. Maa Collector BISHOP”; BPBM.

\section{Description}

Male

Body. Oval, relatively flat dorsally, shiny, closely covered with suberect golden setae. Coloration of body black; antennae and legs dark brown; elytra with indistinct and irregular silver spots consisting of erect setae.

HEAD. Finely punctate, shallowly depressed on dorsum between eyes; distance between eyes as long as eye diameter in dorsal view. 
AntenNAE. Slender and short, reaching about anterior third of pronotum.

Pronotum. Closely and rugosely punctate, with lateral margins almost straight; PW/PL 2.51-2.71 (2.61). Scutellum small, square.

ELYTRA. Oval, widest at base, gently tapered posteriorly; caudal quarter of lateral margins slightly and minutely serrate; EL/EW 1.35-1.40 (1.38); EL / PL 3.77-4.00 (3.88); EW / PW 1.05-1.11 (1.08); TL / EW 1.71-1.75 (1.73).

ABDomen. Sternite VII (Fig. 14A) with two (inner and outer) pairs of long and slender setae and two extra setae, pointed in postero-lateral corners, gently projecting triangularly on mesal part of caudal margin. Sternite VIII (Fig. 14B) small, slightly sclerotized, Y-shaped. Sternite IX (Fig. 14C) wide, gently curved in basal part; apical plates long and slender, pointed at apices.
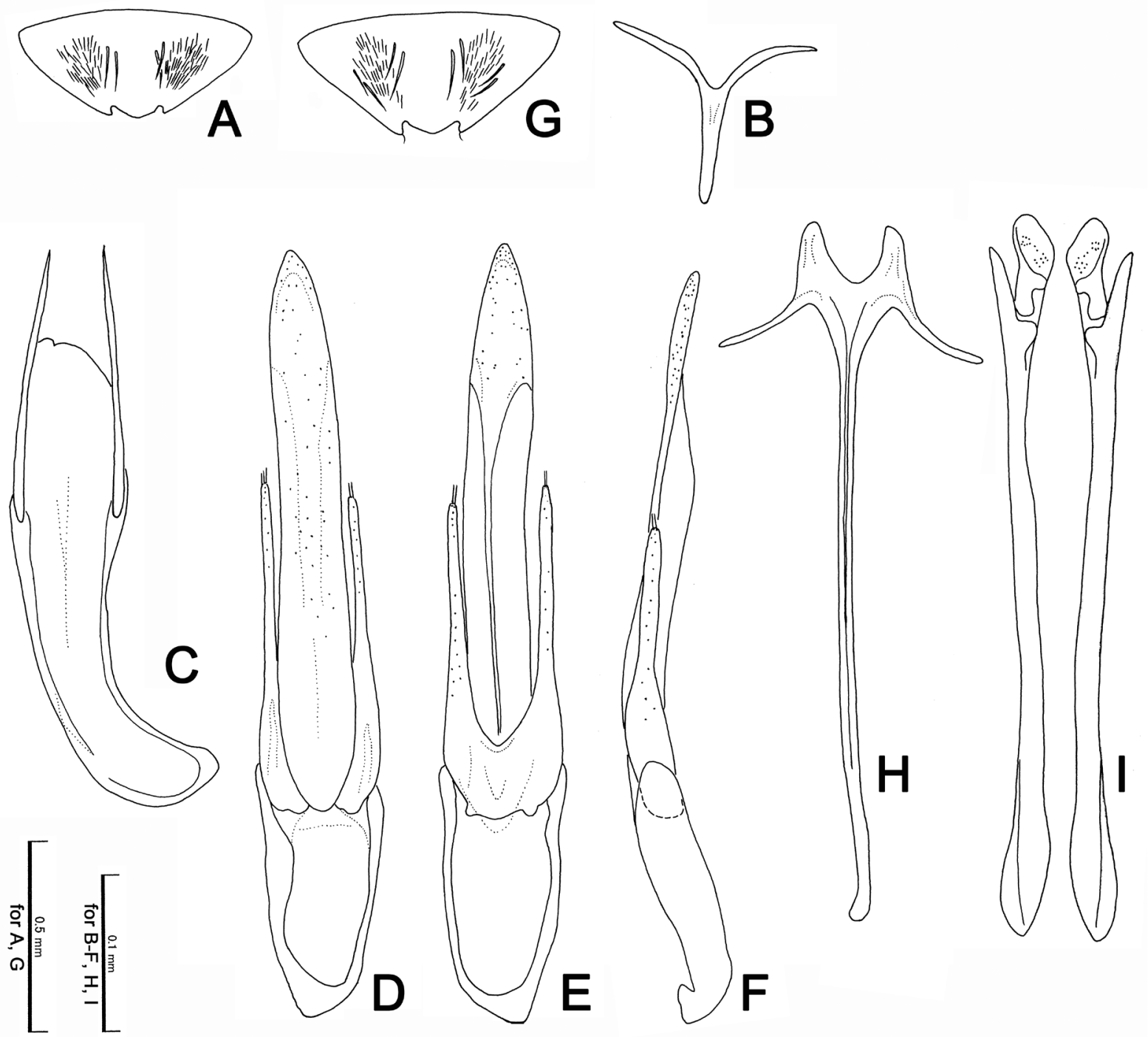

Fig. 14. Mexico papuanus sp. nov., male (A-F) and female (G-I) genitalia (holotype and paratype, BPBM). A, G. Sternite VII. B. Sternite VIII. C. Sternite IX. D. Aedeagus in dorsal view. E. Aedeagus, ventral view. F. Aedeagus, left lateral view. H. Urosternite. I. Ovipositor. 
Aedeagus (Fig. 14D-F). Long, almost symmetrical; basal piece oval; lateral lobes short, with 4 short apical setae; median lobe slender, sparsely punctuate in apical part, slightly expanded in apical quarters, pointed and somewhat prolonged at apex; ventral plates slender, expanded apically, separated to median lobe; ML/BL 2.35; ML/LL 2.61.

\section{Female}

Sexual dimorphism slight. PW/PL 2.38-2.45 (2.42); EL/EW 1.36-1.42 (1.40); EL/ PL 3.70-4.11 (3.85); EW/PW 1.07-1.18 (1.14); TL/EW 1.73-1.79 (1.76). Sternite VII (Fig. 14G) similar to that of male, but postero-lateral corners shallowly concave at apices. Urosternite (Fig. 14H) well sclerotized, Y-shaped, with long and slender apodeme. Ovipositor (Fig. 14I) well sclerotized; coxite sparsely punctuate, rather pointed at apices; apex of baculus bifid; approximate ratio of coxite and baculus $(n=1)$ 1.0: 5.6.

\section{Measurements}

Male ( $\mathrm{n}=2)$ : TL 1.75-2.05 (1.90) mm; PW 0.95-1.08 (1.02) mm; PL 0.35-0.43 (0.39) mm; EL 1.40$1.62(1.51) \mathrm{mm}$; EW 1.00-1.20 (1.10) mm. Female $(\mathrm{n}=3)$ : TL 1.88-2.30 (2.03) mm; PW 0.95-1.10 (1.01) mm; PL 0.40-0.45 (0.42) mm; EL 1.48-1.85 (1.61) mm; EW 1.05-1.30 (1.15) mm.

\section{Distribution}

Papua New Guinea.

\section{Remarks}

This species is distinct in the peculiar form of the male genitalia.

Mexico palauensis sp. nov. urn:1sid:zoobank.org:act:9A734C2D-BF7A-4F05-8628-36655720A091

Figs 11E, 15

\section{Etymology}

This species is named after its type locality.

\section{Material examined}

\section{Holotype}

PALAU • ○̃; “Carp Is. Palau 13-15. IX. 2002 M. Sato leg.”; EUMJ.

\section{Paratypes}

PALAU • 49 ex.; same collection data as for holotype; EUMJ -4 ex.; same collection data as for preceding; NMW • 4 ex.; same collection data as for preceding; BPBM • 1 + , 2 ex.; "Carp Is. Palau 20-VII-2003 K. Takahashi leg."; EUMJ • 1 §, 4 ex.; "Palau Angaur Is. 16-VIII-2003, M. Sato leg.";

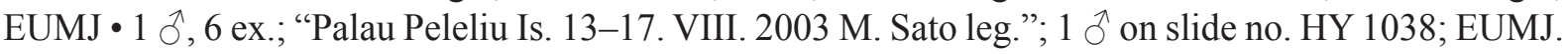

\section{Description}

\section{Male}

Body. Oval, slightly convex dorsally, shiny, closely covered with suberect golden setae. Coloration of body black; elytral silver spots indistinct.

HEAD. Finely punctate, slightly convex on dorsum between eyes; distance between eyes about 0.8 times as long as eye diameter in dorsal view.

ANTENNAE. Very short, reaching about anterior quarter of pronotum. 
Pronotum. Closely punctate, gently arcuate on lateral margins; PW/PL 1.96-2.80 (2.22). Scutellum small, square.

ELYTRA. Oval, widest at base, gently tapered posteriorly; caudal third of lateral margins slightly and indistinctly serrate; EL/EW 0.42-1.43 (1.30); EL/PL 1.13-4.13 (3.14); EW/PW 1.05-1.16 (1.09); TL/EW 0.79-1.87 (1.72).

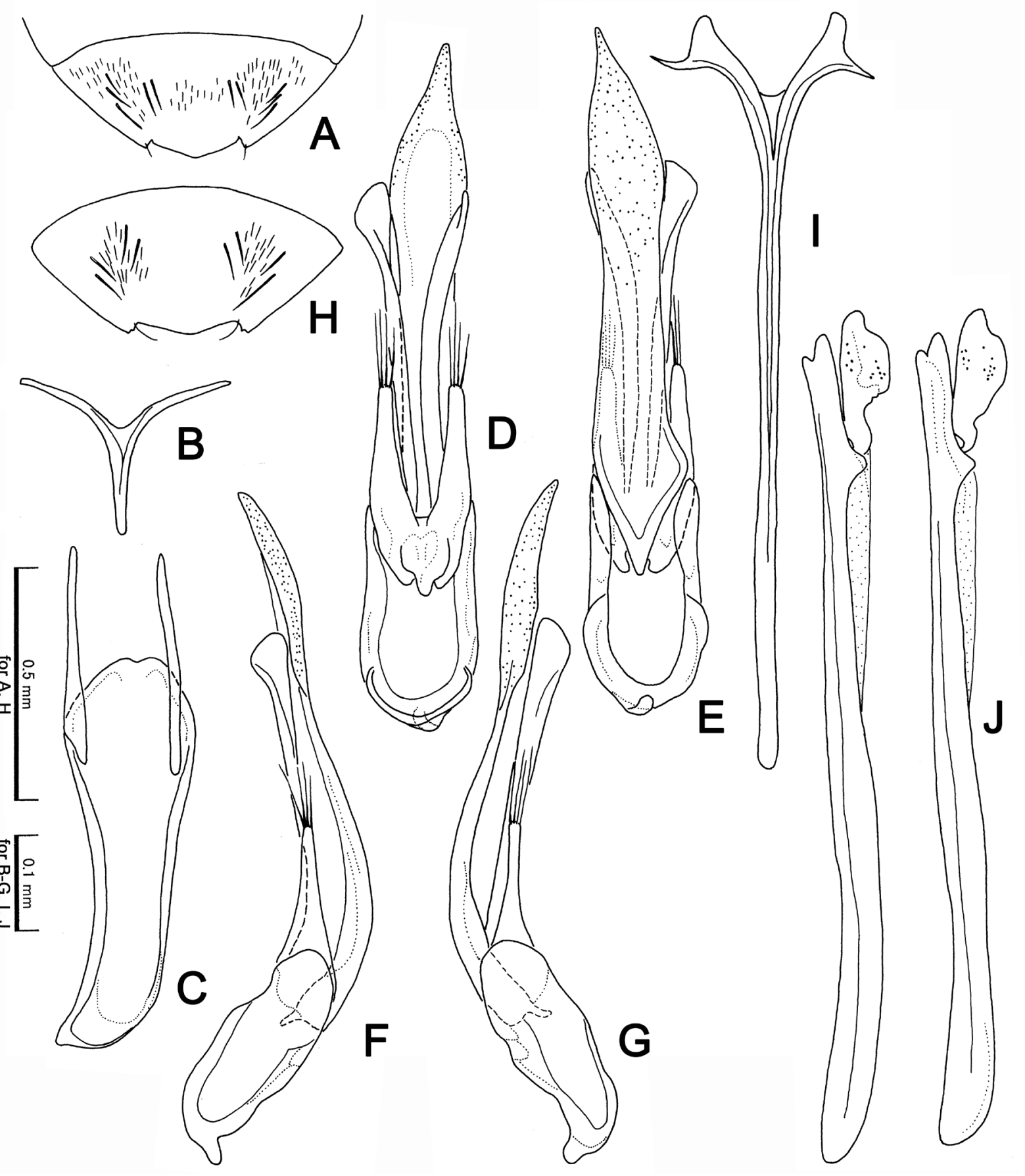

Fig. 15. Mexico palauensis sp. nov., male (A-G) and female (H-J) genitalia (paratypes, EUMJ). A, H. Sternite VII. B. Sternite VIII. C. Sternite IX. D. Aedeagus, ventral view. E. Aedeagus in dorsal view. F. Aedeagus in right lateral view. G. Aedeagus, left lateral view. I. Urosternite. J. Ovipositor. 
AвDOMEN. Sternite VII (Fig. 15A) with two pairs of long and stout extra setae, bearing about 50 long setae, obtuse at postero-lateral corners, pentagonally projecting in median part of caudal margin. Sternite VIII (Fig. 15B) slightly sclerotized, small, Y-shaped. Sternite IX (Fig. 15C) well sclerotized, curved in basal part; apical plates long, pointed at apices.

Aedeagus (Fig. 15D-G). Long and slender, almost symmetrical; basal piece oval, gently tapering basally; lateral lobes relatively long and slender, with $2-3$ very short apical setae, sparsely punctuate; median lobe long, subparallel-sided near base to apical fifth, sparsely punctuate, pointed at apex; ventral plates long and slender, reaching about apical fifth of median lobe, mostly fused to median lobe; ML/BL 2.06; ML/LL 1.92.

\section{Female}

Sexual dimorphism slight. Sternite VII (Fig. 15H) similar to that of male. Urosternite (Fig. 15I) well sclerotized, with long and slender apodeme, with slender lateral projections. Ovipositor (Fig. 15J) well sclerotized; coxite punctuate, obtuse at apices; apex of baculus pointed; approximate ratio of coxite and baculus $(\mathrm{n}=1) 1.0: 6.8$.

\section{Measurements}

Unsexed ( $\mathrm{n}=20)$ : TL 0.85-2.23 (1.93) mm; PW 0.82-1.12 (1.03) mm; PL 0.35-0.55 (0.47) mm; EL 0.45-1.68 (1.46) mm; EW 0.95-1.20 (1.12) mm.

\section{Distribution}

Palau (Carp, Peleliu Islands).

\section{Remarks}

This species is similar to M. borneensis sp. nov. in the shape of the aedeagus, but differs from it in the following characteristics: ventral plates separated from median lobe (attached in M. borneensis sp. nov.) and apical setae on lateral lobes short (long in M. borneensis sp. nov.).

\section{Mexico borneensis sp. nov. urn:lsid:zoobank.org:act:C119FDE3-9A59-4A07-A77A-AF4C067C5D1B}

Figs $11 \mathrm{~A}, 16$

\section{Etymology}

This species is named after its type locality.

\section{Material examined}

Holotype

MALAYSIA • \; "BRITISH N BORNEO Labuan Island Nov. 28-29, 1958”; “Intertidal Zone”; "L. W. Quate Collector"; BPBM.

\section{Paratypes}

MALAYSIA • 1 क; same collection data as for holotype; BPBM $\bullet 1$ o, 1 ex.; "BRITISH N BORNEO Labuan Island Nov. 28-29, 1959"; "Intertidal Zone"; "Maa Collector"; BPBM.

\section{Description}

Male

Body. Oval, slightly convex dorsally, shiny, closely covered with suberect golden setae. Coloration of body black; elytra with small, irregular silver spots consisting of erect setae. 

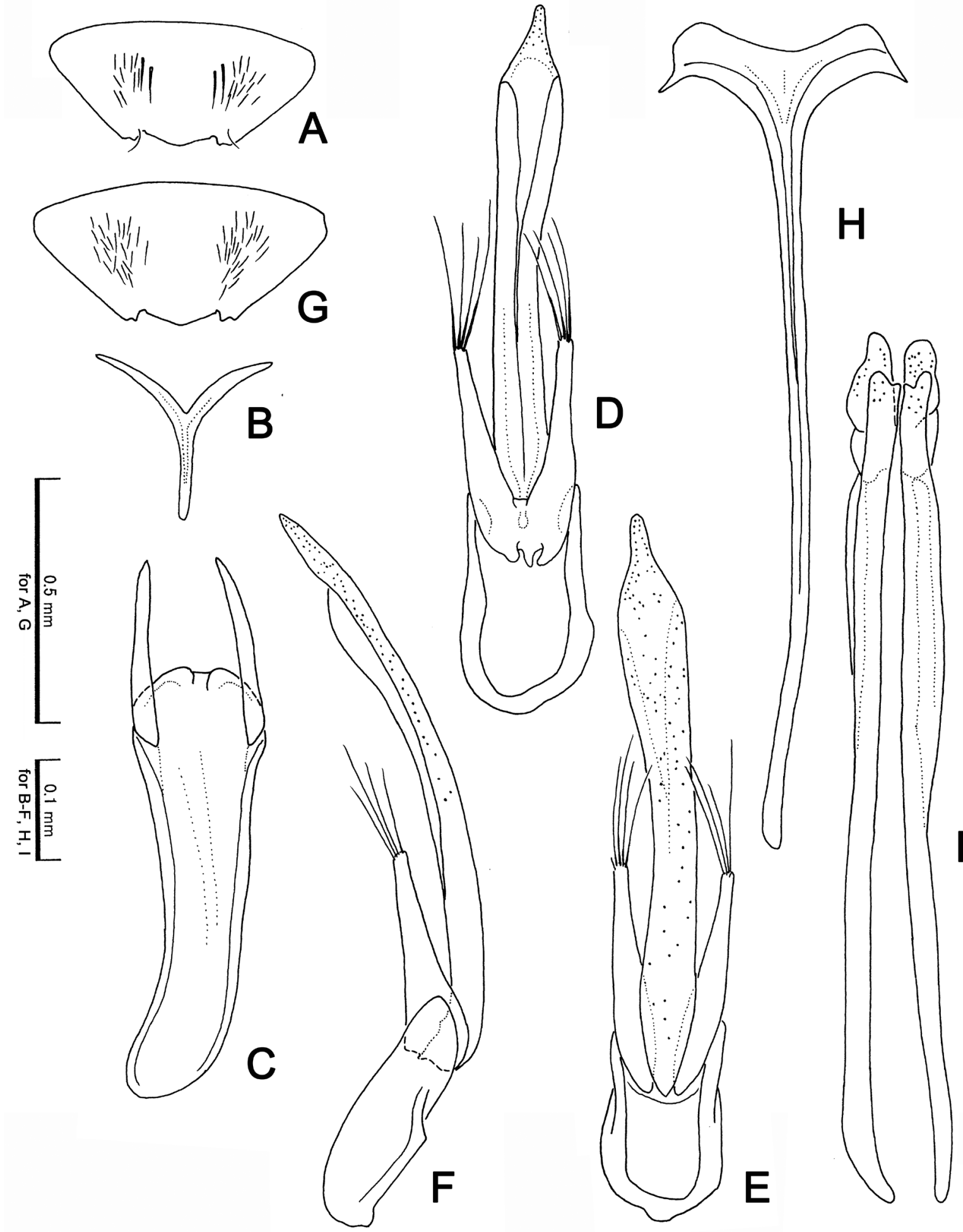

Fig. 16. Mexico borneensis sp. nov., male (A-F) and female (G-I) genitalia (holotype and paratype, BPBM). A, G. Sternite VII. B. Sternite VIII. C. Sternite IX. D. Aedeagus, ventral view. E. Aedeagus in dorsal view. F. Aedeagus in right lateral view. H. Urosternite. I. Ovipositor. 
HeAD. Finely punctate, slightly convex on dorsum between eyes; distance between eyes about 0.8 times as long as eye diameter in dorsal view.

ANTENNAE. Short, reaching about anterior third of pronotum.

Pronotum. Closely punctate; lateral margins gently arcuate; PW / PL 2.04-2.30 (2.20). Scutellum small, square.

ELYTRA. Oval, widest at base, gently tapered posteriorly; caudal quarter of lateral margins slightly and minutely serrate; EL/EW 1.33-1.48 (1.38); EL/PL 3.11-3.70 (3.35); EW/PW 1.09-1.14 (1.11); TL/EW 1.73-1.88 (1.79).

Abdomen. Sternite VII (Fig. 16A) with two pairs of long and stout extra setae, bearing about 20 long setae, bifid in postero-lateral corners, gently projecting triangularly in median part of caudal margin. Sternite VIII (Fig. 16B) small, slightly sclerotized, Y-shaped. Sternite IX (Fig. 16C) well sclerotized, lightly curved in basal part; apical plates long and stout, pointed at apices.

Aedeagus (Fig. 16D-F). Long and slender, almost symmetrical; basal piece oval; lateral lobes short, with 4 apical setae; median lobe long and slender, subparallel-sided near base to near apex, finely punctuate, with nipple-like apex; ventral plates long and slender, reaching about apical tenth of median lobe, mostly fused to median lobe; ML/BL 2.36; ML/LL 2.57.

\section{Female}

Sexual dimorphism slight. Sternite VII (Fig. 16G) similar to that of male, but lacking extra setae. Urosternite (Fig. 16H) well sclerotized, T-shaped, with long and slender apodeme. Ovipositor (Fig. 16I) well sclerotized; coxite sparsely punctuate, obtuse at apices; apex of baculus bifid; approximate ratio of coxite and baculus $(\mathrm{n}=1) 1.0: 5.5$.

\section{Measurements}

Unsexed ( $\mathrm{n}=3$ ): TL 1.70-1.88 (1.81) mm; PW 0.90-0.92 (0.91) mm; PL 0.40-0.45 (0.42) mm; EL 1.301.48 (1.39) mm; EW 0.98-1.05 (1.01) mm.

\section{Distribution}

Malaysia (Labuan Island, off Borneo).

\section{Remarks}

This species is similar to M. baliensis sp. nov. in the shape of the aedeagus, but differs from it in the following characteristics: median lobe pointed at apex (obtuse in M. baliensis sp. nov.) and lateral lobes bearing 4 apical setae ( 3 in M. baliensis sp. nov.).

\section{Mexico taiwanus (Satô, 1994) comb. nov.}

Figs $11 \mathrm{G}, 17$

Babalimnichus taiwanus Satô, 1994: 174.

Babalimnichus masamii - Yoshitomi \& Arai 2004: 23.

\section{Material examined}

JAPAN • 17 ex.; "Hikawa-hama Yonaguni-jima OKINAWA 18. VI. 2001 Koji TOYODA leg."; EUMJ • 4 ex.; "Dannuhama Yonaguni-jima 26-VIII-1994 M. Sato leg."; EUMJ. 


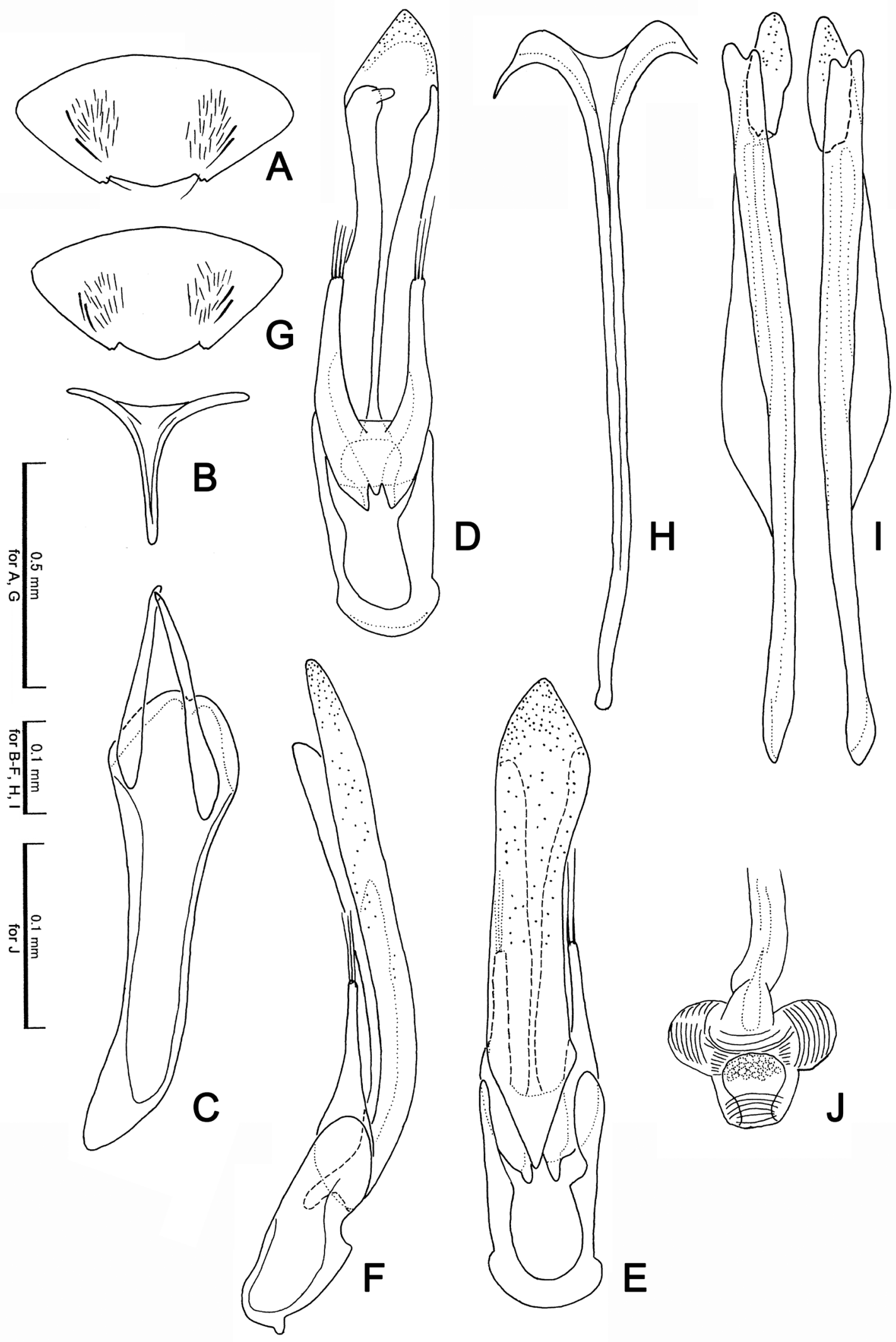

Fig. 17. Mexico taiwanus (Satô, 1994), male (A-F) and female (G-J) genitalia (EUMJ). A, G. Sternite VII. B. Sternite VIII. C. Sternite IX. D. Aedeagus, ventral view. E. Aedeagus in dorsal view. F. Aedeagus in right lateral view. H. Urosternite. I. Ovipositor. J. Spermatheca. 
TAIWAN • 1 วิ, 1 क, 5 ex.; "Lung Keng Pintung Taiwan 10-VIII-2000 M. Sato leg."; EUMJ • 1 ex.; "Mao tantou Pintung, Taiwan 10-VIII-2000 M. Sato leg."; EUMJ • 1 ex.; "Lutao Taiwan 26-28. III. 1998 M. Sato leg."; EUMJ • 5 ex.; "Lanhsu Taiwan 5-10. VIII. 1998 M. Sato leg."; EUMJ • 3 ex., in ethanol; "Fushan Village Donghe Township, Taitung Country, Taiwan 1-V-2013 Tatsuya Niisato leg."; EUMJ.

\section{Redescription}

Male

For a detailed description of the external features, see the original description (Satô 1994). PW/PL 1.67-2.44 (2.00); EL/EW 1.18-1.42 (1.32); EL/PL 2.33-3.40 (2.87); EW/PW 1.00-1.15 (1.09); TL/EW 1.59-1.92 (1.78).

Sternite VII (Fig. 17A) with two pairs of long, stout extra setae, bearing about 20 long setae, bifid in postero-lateral corners, gently projecting triangularly in median part of caudal margin. Sternite VIII (Fig. 17B) small, slightly sclerotized, Y-shaped. Sternite IX (Fig. 17C) slender, lightly curved in basal part; apical plates long and slender, pointed at apices. Aedeagus (Fig. 17D-F) relatively short, asymmetrical; basal piece oval; lateral lobes short, with 2-4 apical setae; median lobe a little wide, sparsely punctuate in apical part, slightly expanded in apical quarter, pointed at apex; ventral plates relatively slender, separated from median lobe, left one with thumb-like projection on inner margin of apex; ML/BL 2.42; ML/LL 2.42.

\section{Female}

Sexual dimorphism slight. Sternite VII (Fig. 17G) similar to that of male. Urosternite (Fig. 17H) well sclerotized, with long and slender apodeme, T-shaped. Ovipositor (Fig. 17I) well sclerotized; coxite sparsely punctuate, rather pointed at apices; apices of baculus bifid; approximate ratio of coxite and baculus $(\mathrm{n}=1) 1.0: 5.3$.

\section{Measurements}

Unsexed (n = 20): TL 1.68-2.17 (1.95) mm; PW 0.90-1.10 (1.01) mm; PL 0.40-0.60 (0.51) mm; EL 1.28-1.62 (1.44) mm; EW 1.00-1.15 (1.10) mm.

\section{Distribution}

Taiwan (including Lutao and Lanhsu Islands), Japan (Yonaguni-jima).

\section{Remarks}

This is the first record of this species from Lutao and Lanhsu Islands, off Taiwan, and Yonaguni-jima.

Mexico masamii (Satô, 1994) comb. nov.

Figs 11F, 18-19

Babalimnichus masamii Satô, 1994: 175.

Babalimnichus masamii - Yoshitomi \& Satô 2001: 472 [larval description]. — Yoshitomi 2014a: 29. — Ono et al. 2012: 47. — Kamezawa 2017: 54.

\section{Material examined}

JAPAN • 7 ex.; "Japan: Honshû Nanaura-kaigan Tachibana, Sado-shi Niigata, 5. vi. 2016 37.986591, 138.234143 Kamezawa H. leg."; EUMJ • 1 đ; "[IZ9] Ishijirogawa, Shikinejima, Izu Isls., Japan, 34¹9.409" N, 139¹3.308" E, ca 16 m, 7. II. 2013, H. Yoshitomi leg."; EUMJ • 1 o, 1 q, 14 ex.; "Kariya-kaigan Tokoname-shi Aichi Pref. 17. VIII. 1995, 17. VIII. 1995 H. Yoshitomi leg."; 1 ô and 1 q 
on slides HY 989, 992-994; EUMJ • 1 ex.; "Zoubigasaki, Murozumi Hikari-shi Yamaguchi Pref., Jpn 28. VII. 2005 Y. Fujitani leg."; EUMJ • 5 ex.; "Bashayamamura Amami-oshima 3-V-1999 M. Sato leg.”; EUMJ • 28 ex.; "Kawata Okinawa 5-V-1999 M. Sato leg."; EUMJ • 9 ex.; "Kim-kaigan Okinawa 28III-1997 M. Satô leg."; EUMJ • 1 ex.; "Onnason Okinawa-jima 26-28. IV. 2004 M. Sato leg."; EUMJ • 1 ex.; "Kume-jima Ryukyu 30-IV-2004 M. Sato leg."; EUMJ • 2 ex.; "Tomori Ryukyus Miyako-jima

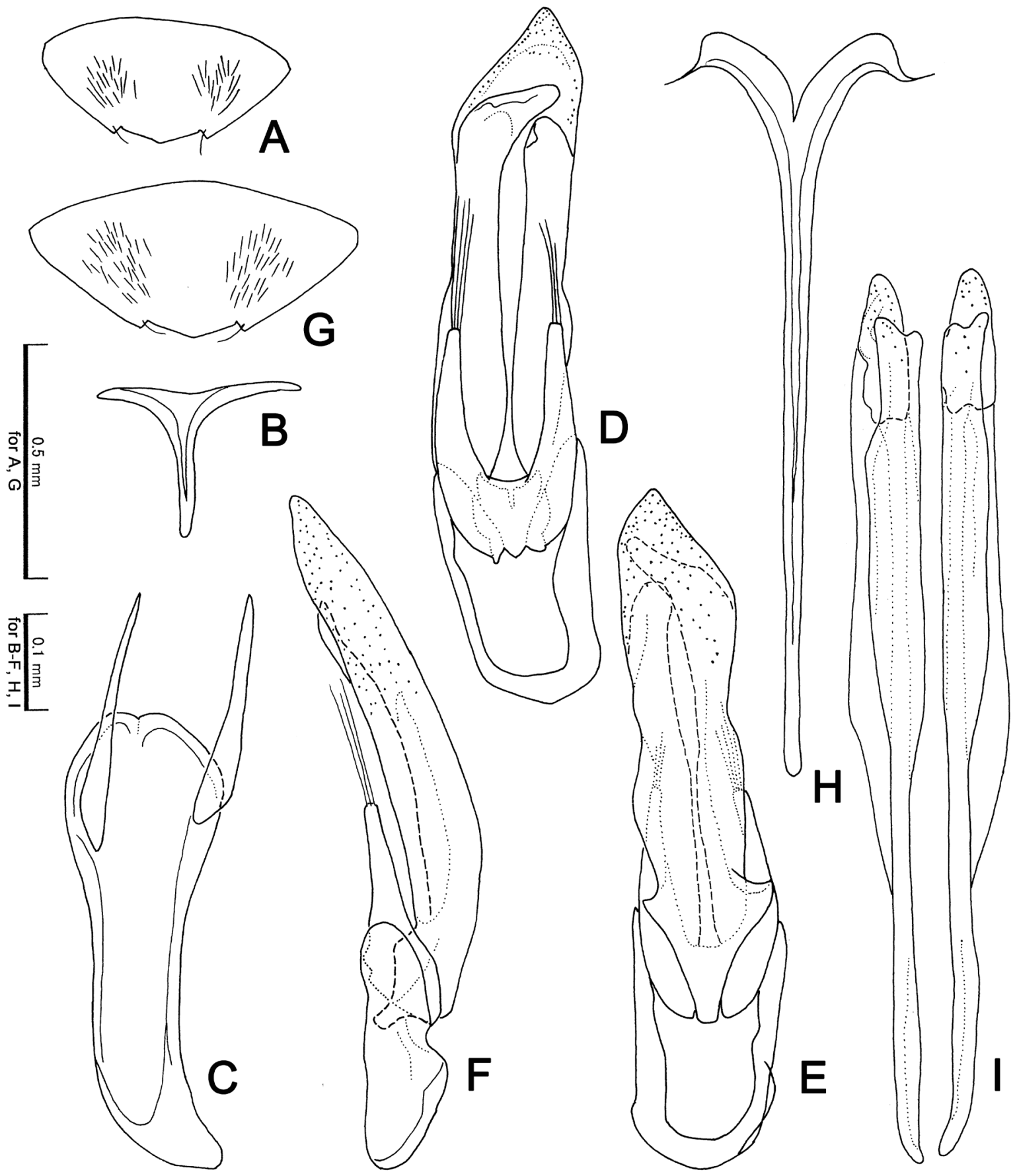

Fig. 18. Mexico masamii (Satô, 1994), male (A-F) and female (G-J) genitalia (EUMJ). A, G. Sternite VII. B. Sternite VIII. C. Sternite IX. D. Aedeagus, ventral view. E. Aedeagus in dorsal view. F. Aedeagus in right lateral view. H. Urosternite. I. Ovipositor. 
7-V-1998 M. Satô leg.”; EUMJ • 13 ex.; "Uganzaki Ishigaki 22-IX-2003 M. Sato leg.”; EUMJ • 7 ex., in ethanol; "Sakaura, Izumo, Shimane 31. VII. 2006 M. Hayashi"; EUMJ • 2 pupae, with larval skins, in ethanol; "Nahama-kaigan, Nagai, Yokosuka-shi Kanagawa Pref., Japan 6. July 2007 M. Asano leg."; EUMJ.

\section{Redescription}

\section{Male}

For a detailed description of the external features, see the original description (Satô 1994). PW/ PL 1.672.22(1.99); EL/EW 1.27-1.48(1.36); EL/PL 2.64-3.29(2.96); EW/PW 1.00-1.18(1.10); TL/EW 1.71$1.95(1.82)$.

Sternite VII (Fig. 18A) bearing about 30 long setae, lacking extra setae; postero-lateral corners short and pointed; median part of caudal margin gently projecting triangularly. Sternite VIII (Fig. 18B) small, slightly sclerotized, Y-shaped. Sternite IX (Fig. 18C) well sclerotized, curved in basal part, shallowly concave at apex; apical plates rather stout, pointed at apices. Aedeagus (Fig. 18D-F) relatively short, asymmetrical; basal piece oval; lateral lobes short, with 3-4 apical setae; median lobe wide, sparsely punctuate in apical part, expanded in apical quarter, gently pointed at apex; ventral plates wide, separated from median lobe, left one long and curved interiorly in apical part, right one short and straight; ML/BL 2.24; ML/LL 2.43.

\section{Female}

Sexual dimorphism slight. Sternite VII (Fig. 18G) similar to that of male. Urosternite (Fig. 18H) well sclerotized, T-shaped, with long and slender apodeme. Ovipositor (Fig. 18I) well sclerotized; coxite sparsely punctuate, rather pointed at apices; apex of baculus bifid; approximate ratio of coxite and baculus $(\mathrm{n}=1) 1.0: 5.9$.

\section{Pupae}

Body (Fig. 19) about $1.5 \mathrm{~mm}$, cream-colored, bearing long setae on head, pronotum, elytra and abdomen.
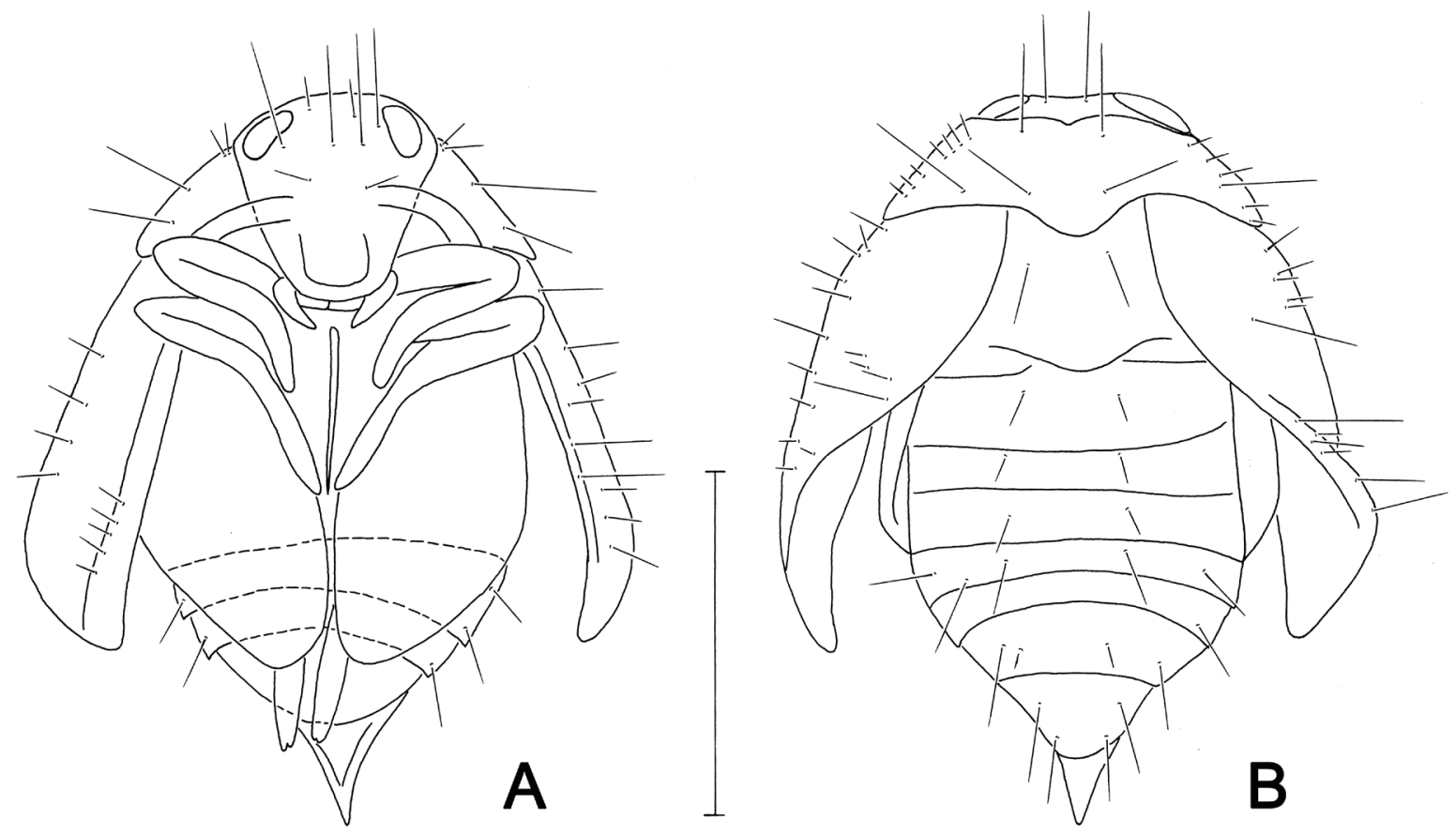

Fig. 19. Pupa of Mexico masamii (Satô, 1994). A. Ventral aspect. B. Dorsal aspect. Scale bar: $1.0 \mathrm{~mm}$. 


\section{Measurements}

Unsexed (n = 20): TL 1.82-2.32 (2.04) mm; PW 0.90-1.10 (1.02) mm; PL 0.45-0.60 (0.52) mm; EL 1.32-1.72 (1.53) mm; EW 1.00-1.30 (1.12) mm.

\section{Distribution}

Japan (Honshu, Sadogashima, Izu Islands (Shikine-jima, Kozu-shima), Shikoku, Kyushu, the Ryukyus (Yakushima, Amami-Ôshima, Tokuno-shima, Okinoerabu-jima, Yoron-tô, Okinawa-jima, Irabu-jima, Kume-jima, Miyako-jima, Ishigaki-jima)).

\section{Remarks}

I re-examined the specimens from Yonaguni-jima (Yoshitomi \& Arai 2004), and it is clear that they do not represent this species but the preceding one. This is the first record of this species from Kume-jima.

This species has the northernmost distribution (Sado Island) in the subfamily Thaumastodinae (Kamezawa 2017).

\section{Biological notes}

Overwintering takes place in the larval stage in Chiba Prefecture (Ono et al. 2012) or the adult stage on the Izu Islands (Yoshitomi 2014a).

Mexico splendens (Hernando \& Ribera, 2003) comb. nov.

Babalimnichus splendens Hernando \& Ribera, 2003: 270.

\section{Distribution}

Tonga Islands.

\section{Remarks}

This species was described based on the female holotype. No additional specimens have been found.

\section{Phylogeny}

As a result of my analysis, one most parsimonious tree was obtained $(\mathrm{L}=17, \mathrm{Ci}=88, \mathrm{Ri}=60)$, shown in Fig. 20. The synapomorphies of the subfamily Thaumastodinae are as follows: oblong body shape (1-1); eyes large, situated on dorso-lateral side of head (3-1); and hind legs with tibial spurs (9-1).

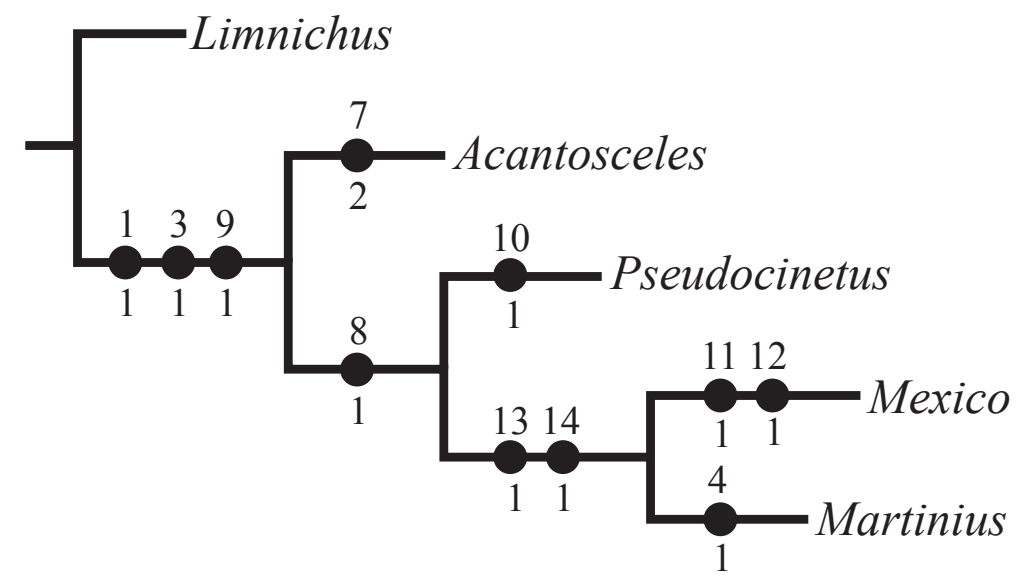

Fig. 20. Most parsimonious tree. 


\section{Discussion}

In the present paper, I have reviewed the Asian species and genera of the subfamily Thaumastodinae, and recognized three genera and 25 species (adding seven new species) from this area.

Acontosceles is an Oriental genus, living in freshwater habitats. Some unnamed species were known (Pütz 2008) because the distributional area of each species is limited and some populations were represented by female specimens only. Some new species will be described in the near future.

Pseudeucinetus is also an Oriental genus, living in freshwater habitats. The adults of this genus are frequently attracted to light, and the distributional area of $P$. zygops is wide, from India to Indonesia.

Mexico is known as a Neotropical genus, and it is newly recorded from Asia in this study. The habitat of this genus is rocky seashores, and the distributional area is mainly the Oriental and the Neotropical, extending to the Palearctic (coastal area of Japan) and the Australian (Tonga Islands) Regions. The pattern is probably not a disjunct distribution, but rather a wide distribution in the Pacific. Undescribed species are expected to be found from unrecorded areas and countries, e.g., Indochina, the Philippines, many islands of Indonesia, Australia, New Caledonia and the Pacific Islands.

Martinius is a Neotropical genus, represented by three species. This genus shows a sister group relationship with the genus Mexico (Fig. 20).

Taking into consideration the factors mentioned above, Thaumastodinae does not seem to be an example of disjunct distribution. It is probable that the main distribution area of the subfamily is the Oriental Region, and it has spread to parts of the Pacific, the Palearctic, the Australian and the Neotropical areas.

In a preliminary phylogenetic analysis using morphological characters of nine genera in four subfamilies, the monophyly of the family Limnichidae was not supported (unpublished data). In addition, the monophyly of the subfamily Limnichinae, the most diverse subfamily within the family, was also doubtful as already mentioned by Hernando \& Ribera (2005a). This subfamily is subdivided into three tribes, Bothriophorini, Limnichini and Wooldridgeni, and one genus group (Mandersia group, sensu Hernando \& Ribera 2005b) in Limnichini. Most of the genera in the subfamily Limnichinae are classified in the tribe Limnichini without a tribal definition. It is suggested that the family Limnichidae is a paraphyletic group, and the definition of the family must be reconstructed, including related families such as Heteroceridae (Crowson, 1978), Chelonariidae (Kundrata et al. 2017), or Dryopidae (Costa et al. 1999).

\section{Acknowledgements}

Field research and collection in Hahajima was with permission of the Japan Environmental Agency, Ogasawara Board of Education, Tokyo Metropolis, and the Agency for Cultural Affairs. I thank Dr Toshio Kishimoto, Dr Tatsuya Niisato, Dr Manfred Jäch (NMW), Dr Ming-Luen Jeng (NMNS), the late Dr Masataka Satô, Dr Masami Hayashi, Dr Masakazu Hayashi, Dr Kiyoshi Ando, Dr Keiichi Takahashi, Dr Makoto Asano, Mr Hiroyuki Wakahara, Mr Hiromu Kamezawa, Mr Koji Arai, Dr Matthias Hartmann (NME) and Mr Shepherd Myers (BPBM) for supplying the material used in this paper, and Mr Dennis Murphy (The United Graduate School of Agricultural Sciences, Ehime University) for his critical reading of the draft. Part of this study was supported by KAKENHI (24510333; head investigator: H. Kojima).

\section{References}

Beutel R.G. 1995. Phylogenetic analysis of Elateriformia (Coleoptera: Polyphaga) based on larval characters. Journal of Zoological Systematics and Evolutionary Research 33: 145-171.

https://doi.org/10.1111/j.1439-0469.1995.tb00222.x 
Champion G.C. 1924a. On a new subfamily of clavicorn Coleoptera. Entomologist's Monthly Magazine 60: 25-29.

Champion G.C. 1924b. Thaumastodus fusiformis Champ.: Synonymical note. Entomologist's Monthly Magazine 60: 116-117.

Costa C., Vanin S.A. \& Ide S. 1999. Systematics and bionomics of Cneoglossidae with a cladistic analysis of Byrrhoidea sensu Lawrence \& Newton (1995) (Coleoptera, Elateriformia). Arquivos de Zoologia, Sao Paulo 35: 231-300. https://doi.org/10.11606/issn.2176-7793.v35i3p231-300

Crowson R.A. 1978. Problems of phylogenetic relationships in Dryopoidea (Coleoptera). Entomologica Germanica 4: 250-257.

Goloboff P. 1999. NONA (NO NAME) ver. 2.0. Published by the author, Tucumán, Argentina.

Heller K.M. 1921. Philippinische Melandryidae. Entomologische Blätter 17 (10-12): 155-157.

Hernando C. \& Ribera I. 2003. Babalimnichus splendens sp. n., a new jumping shore beetle from the Tonga Islands (Polynesia) (Coleoptera: Limnichidae, Thaumastodinae). Koleopterologische Rundschau 73: 269-273.

Hernando C. \& Ribera I. 2005a. 18.5. Limnichidae Erichson, 1846. In: Beutel R.G. \& Leschen R.A.B. (eds) Handbook of Zoology, Volume IV (Part 38), Coleoptera, Beetles, Volume 1: Morphology and Systematics (Archostemata, Adephaga, Myxophaga, Polyphaga partim): 512-518. Walter de Gruyter, Berlin.

Hernando C. \& Ribera I. 2005b. Pseudothryptus, a new genus of Limnichidae (Coleoptera) for Caccothryptus multiseriatus. Entomological Problems 35: 131-135.

Hinton H.E. 1939. An inquiry into the natural classification of the Dryopoidea, based partly on a study of their internal anatomy (Col.). Transactions of the Royal Entomological Society of London 89: 133-184. https://doi.org/10.1111/j.1365-2311.1939.tb00739.x

Jäch M.A. 1998. Annotated check list of aquatic and riparian/littoral beetle families of the world (Coleoptera). In: Jäch M.A. \& Ji L. (eds) Water Beetles of China, Volume II: 25-42. ZoologischBotanische Gesellschaft in Österreich/Wiener Coleopterologenverein, Vienna.

Kamezawa H. 2017. Collecting record of Babalimnichus masamii from Sado Islands. Sayabane, New Series (25): 54. [In Japanese.]

Kundrata R., Jäch M.A. \& Bocak L. 2017. Molecular phylogeny of the Byrrhoidea-Buprestoidea complex (Coleoptera, Elateriformia). Zoologica Scripta 46 (2): 150-164. https://doi.org/10.1111/zsc.12196

Lawrence J.F. 1988. Rhinorhipidae, a new beetle family from Australia, with comments on the phylogeny of Elateriformia. Invertebrate Taxonomy 2 (1): 1-53.

Nixon K.C. 2002. WinClada ver. 1.00.08. Published by the author, Ithaca, NY.

Ono H., Kamezawa H. \& Sugaya K. 2012. Record of two seashore beetles from Chiba Prefecture. Sayabane, New Series (5): 47-48. [In Japanese.]

Pütz A. 2008. Zur Kenntnis der Gattung Acontosceles Champion, 1924 (Coleoptera: Limnichidae: Thaumastodinae). Koleopterologische Rundschau 78: 305-327.

Satô M. 1965. The limnichid-beetles of Formosa. Special Bulletin of the Lepidopterists Society of Japan (1): 121-125.

Satô M. 1966. The limnichid-beetles of Japan. Transactions of the Shikoku Entomological Society 9 (2): $55-62$. 
Satô M. 1994. Note on the genus Pseudeucinetus Heller and its new relative (Coleoptera, Limnichidae). Special Bulletin of the Essa Entomological Society 2: 173-177.

Skelley P.E. 2005. A new species of 'jumping shore beetle' in the genus Mexico Spilman from the Bahamas (Coleoptera: Limnichidae: Thaumastodinae). Insecta Mundi 19 (1-2): 119-122.

Spangler P.J. 1995. A review and two new species of the genus Pseudeucinetus Heller from southeast Asia and a world checklist of the Thaumastodinae (Coleoptera: Limnichidae). Special Bulletin of the Japanese Society of Coleopterology 4: 395-405.

Spangler P.J., Staines C.L., Spangler P.M. \& Staines S.L. 2001. A checklist of the Limnichidae and the Lutrochidae (Coleoptera) of the world. Insecta Mundi 15 (3): 151-165.

Spilman T.J. 1959. A study of the Thaumastodinae, with one new genus and two new species (Limnichidae). Coleopterist's Bulletin 13: 111-122.

Spilman T.J. 1966. A new species of Martinius from Cuba (Coleoptera: Limnichidae). Coleopterist's Bulletin 20: 123-125.

Spilman T.J. 1972. A new genus and species of jumping shore beetle from Mexico. Pan-Pacific Entomologist 48: 108-115.

Wooldridge D.P. 1988. Martinius temporalis, a new species from Ecuador (Coleoptera: Limnichidae: Thaumastodinae). Journal of the New York Entomological Society 96: 314-315.

Yoshitomi H. 2004. A new record of Pseudeucinetus zygops (Coleoptera, Limnichidae) from Indonesia. Elytra, Tokyo 32: 420.

Yoshitomi H. 2008. Contribution to the taxonomy of the genus Laius Guérin-Méneville in Indonesia, with description of a new species (Coleoptera: Malachiidae). Koleopterologische Rundschau 78: 285290.

Yoshitomi H. 2014a. Water beetle fauna of Izu Islands. Sayabane, New Series (16): 26-31. [In Japanese, with English summary.]

Yoshitomi H. 2014b. Comparative morphology of the endophallic structures of the genus Laius (Coleoptera, Melyridae), with the descriptions of three new species. European Journal of Taxonomy 97: 1-29. https://doi.org/10.5852/ejt.2014.97

Yoshitomi H. \& Arai K. 2004. Babalimnichus masamii collected from Yonaguni-jima. Coleopterists' News (148): 23. [In Japanese.]

Yoshitomi H. \& Putra N.S. 2010. Two new species of the genus Pseudeucinetus Heller from Indonesia and the Solomon Islands (Coleoptera: Limnichidae: Thaumastodinae). Koleopterologische Rundschau 80: $143-150$.

Yoshitomi H. \& Putra N.S. 2011. A new species of the genus Acontosceles (Coleoptera, Limnichidae, Thaumastodinae) from Indonesia. Bonn Zoological Bulletin 60 (2): 165-168.

Yoshitomi H. \& Satô M. 2001. Description of the larva of Babalimnichus masamii M. Sato (Coleoptera: Limnichidae, Thaumastodinae). Coleopterist's Bulletin 55: 471-474.

Yoshitomi H. \& Satô M. 2005. A new species of the genus Acontosceles (Coleoptera, Limnichidae) from Laos, with the description of the genitalia of A. yorioi M. Satô. Elytra, Tokyo 33: 34-41. 
Published on: 4 December 2019

Topic editor: Gavin Broad

Section editor: Max Barclay

Desk editor: Kristiaan Hoedemakers

Printed versions of all papers are also deposited in the libraries of the institutes that are members of the EJT consortium: Muséum national d'histoire naturelle, Paris, France; Meise Botanic Garden, Belgium; Royal Museum for Central Africa, Tervuren, Belgium; Royal Belgian Institute of Natural Sciences, Brussels, Belgium; Natural History Museum of Denmark, Copenhagen, Denmark; Naturalis Biodiversity Center, Leiden, the Netherlands; Museo Nacional de Ciencias Naturales-CSIC, Madrid, Spain; Real Jardín Botánico de Madrid CSIC, Spain; Zoological Research Museum Alexander Koenig, Bonn, Germany; National Museum, Prague, Czech Republic. 


\section{Appendix 1}

\section{List of the species of Thaumastodinae of the world}

Subfamily Thaumastodinae Champion, 1924

urn:1sid:zoobank.org:act:19F0D808-0024-490C-8253-5486727F9C9B

Genus Acontosceles Champion, 1924

urn:1sid:zoobank.org:act:22065D0C-EF27-45ED-9A42-3FF6BBD1F02C

Acontosceles hydroporoides species group (sensu Pütz 2008)

Acontosceles borneensis sp. nov. (Malaysia [Borneo])

urn:Isid:zoobank.org:act:2582F411-8790-4937-B6A0-248899FD9208

Acontosceles chujoi Yoshitomi \& Satô, 2005 (Laos, Vietnam)

urn:1sid:zoobank.org:act:32D060AE-982D-41F3-924D-92A1096AE4CE

Acontosceles hydroporoides Champion, 1924 (India)

urn:1sid:zoobank.org:act:F46F765F-6E3D-4AD2-AAD2-C13F5C261B6E

Acontosceles jaechi Pütz, 2008 (Philippines [Bohol])

urn:1sid:zoobank.org:act:255AAD2A-DA25-4E3C-909F-D1618D5EB13A

Acontosceles javanicus Yoshitomi \& Putra, 2011 (Indonesia [Java])

urn:1sid:zoobank.org:act:A8492B62-6953-445C-AF68-25460E7CB19D

Acontosceles negrosensis Pütz, 2008 (Philippines [Negros])

urn:1sid:zoobank.org:act:557BCBC3-8F92-47A9-983E-F9518491A6E3

Acontosceles tagalog Spilman, 1959 (Philippines)

urn:1sid:zoobank.org:act:EBC9A1BA-BB26-4C12-B5BA-6815D1F99ECB

Acontosceles yorioi Satô, 1966 (Japan [Okinawa-jima, Iriomote-jima], Taiwan)

urn:1sid:zoobank.org:act:4D9B9FFD-44E4-4A1F-84FA-E7173E64A7D8

Acontosceles quatuordecimmaculosus species group (sensu Pütz 2008)

Acontosceles quatuordecimmaculosus Pütz, 2008 (Myanmar)

urn:1sid:zoobank.org:act:1EE4A8B9-22A6-42E4-8F51-DBD1B77B4B88

Acontosceles siwalikensis Pütz, 2008 (Nepal)

urn:1sid:zoobank.org:act:9AE002BE-1FEF-4FB8-A3B5-A8943CB1989C

Acontosceles yunnanensis Pütz, 2008 (China [Yunnan])

urn:1sid:zoobank.org:act:64F5AC37-E237-4C0C-9615-DDB748F577C4

Acontosceles zetteli Pütz, 2008 (Thailand, Laos)

urn:1sid:zoobank.org:act:5D994D2B-317D-48B7-9AA0-3271DE288BF2

Genus Martinius Spilman, 1959

urn:lsid:zoobank.org:act:D1657311-552F-4517-9F3E-204464C12109

Martinius ripisaltator Spilman, 1966 (Cuba)

urn:1sid:zoobank.org:act:5BF966A0-9A9A-4156-904B-F4C3561AEC2D

Martinius tellipontis Spilman, 1959 (Panama)

urn:lsid:zoobank.org:act:1A894F79-DE95-4846-952B-039B426CC41E

Martinius temporalis Wooldridge, 1988 (Ecuador)

urn:1sid:zoobank.org:act:E93DD6FC-2356-437F-882E-80909CC5E68B 
Genus Mexico Spilman, 1972

urn:1sid:zoobank.org:act:A7037F96-6A97-4838-A4B5-A3D090307D6C

Mexico baliensis sp. nov. (Indonesia [Bali Island])

urn:1sid:zoobank.org:act:98D64DE9-6A33-4EBF-A7F9-26F9A7BA409E

Mexico borneensis sp. nov. (Malaysia [Borneo])

urn:1sid:zoobank.org:act:C119FDE3-9A59-4A07-A77A-AF4C067C5D1B

Mexico litoralis Spilman, 1972 (Mexico)

urn:1sid:zoobank.org:act:10667682-8B8C-4E02-9AC3-678D8B291954

Mexico masamii (Satô, 1994) (Japan [Honshu, Izu Islands, Shikoku, Kyushu, the Ryukyus])

urn:1sid:zoobank.org:act:85474634-5E5A-4F83-AD88-EDA6242183A0

Mexico morrisoni Skelley, 2005 (Bahamas)

urn:1sid:zoobank.org:act:0D1B37BE-BF21-4679-A711-2B0C15A6AC96

Mexico ogasawaraensis sp. nov. (Japan [Ogasawara Islands])

urn:1sid:zoobank.org:act:8B1989C3-5D1B-4E9C-A87F-0ED19524F6D4

Mexico palauensis sp. nov. (Palau)

urn:1sid:zoobank.org:act:9A734C2D-BF7A-4F05-8628-36655720A091

Mexico papuanus sp. nov. (Papua New Guinea)

urn:1sid:zoobank.org:act:DB69DE47-18E6-4FA0-8D94-A9A95470D78E

Mexico splendens (Hernando \& Ribera, 2003) (Tonga Islands)

urn:1sid:zoobank.org:act:119CC677-2FBF-4117-B0DA-3931B3A6CDF1

Mexico taiwanus (Satô, 1994) (Taiwan, Japan [Yonaguni-jima])

urn:1sid:zoobank.org:act:CBAA7928-BE17-4A2B-AF43-1E2D35FBD09E

Genus Pseudeucinetus Heller, 1921

urn:1sid:zoobank.org:act:08D0E4C3-6D24-4A42-BB38-961E6BA85773

Pseudeucinetus javanicus Yoshitomi \& Putra, 2010 (Indonesia [Java, Lombok])

urn:1sid:zoobank.org:act:9766FA9E-388C-455E-883E-7FEF7DE27D2A

Pseudeucinetus novabritannica Delève, 1973 (Bismarck Archipelago [New Britain])

urn:1sid:zoobank.org:act:D4F058A4-8841-48EF-B1EA-03BA40B1B6E2

Pseudeucinetus papuanus sp. nov. (Papua New Guinea)

urn:1sid:zoobank.org:act:978D5D6D-8D48-425D-AB1B-0536A2E10753

Pseudeucinetus solomonicus Yoshitomi \& Putra, 2010 (Solomon Islands [Santa Catalina, Santa Anna]) urn:1sid:zoobank.org:act:113B8D47-F5AA-4EC7-8F07-9921CB8347D8

Pseudeucinetus spilmani Spangler, 1995 (Indonesia [Bacan])

urn:1sid:zoobank.org:act:9DAB932B-0495-4EE9-B97D-AAA873871A2E

Pseudeucinetus uenoi Spangler, 1995 (Malaysia [Borneo])

urn:1sid:zoobank.org:act:5CC8AB17-8B02-4170-97C2-7A18F85D751D

Pseudeucinetus zygops Heller, 1921 (India, Malaysian Peninsula, Bismarck Islands [New Ireland], the Philippines [Balabac, Palawan, Mindanao, Negros], Indonesia [Sulawesi])

urn:1sid:zoobank.org:act:7903C913-85A7-4AE6-B4E4-619A86BB46CB 


\section{Appendix 2}

\section{Characters used in the phylogenetic analysis}

Character 1. Body shape: oval (0); oblong (1).

Character 2. Reception of legs in venter: absent (0); present (1)

Character 3. Eyes: moderate size, situated on lateral side of head ( 0$)$; large size, situated on dorso-lateral side of head (1).

Character 4. Antennal segments: 11 (0); 7 (1).

Character 5. Antennae inserted: near eyes (0); near mandibles (1).

Character 6. Antennal groove on gena: absent (0); present (1).

Character 7. Tarsal formula: 5-5-5 (0); 4-4-4 (1); 4-5-5 (2).

Character 8 . Hind coxa: normally visible ventrally $(0)$; hidden by hind coxal plate and invisible ventrally $(0)$.

Character 9. Hind legs: without tibial spurs (0); with tibial spurs (1).

Character 10. Male fore tarsi: normal (0); enlarged (1).

Character 11. Aedeagus: without extra plate (0); with ventral plates (1).

Character 12. Male genitalia: lateral lobe with short setae and punctures (0); with extra long setae (1).

Character 13. Male genitalia: medial lobe shorter than lateral lobe (0); longer than lateral lobe (1).

Character 14. Female genitalia: coxite pointed at apex, attached in apical part of bacillus (0); obtuse and bifid at apex, attached in apical sixth of baculus (1). 


\section{Appendix 3}

Data matrix for phylogenetic analysis

\begin{tabular}{ccccccccccccccc}
\hline Character no. & $\mathbf{1}$ & $\mathbf{2}$ & $\mathbf{3}$ & $\mathbf{4}$ & $\mathbf{5}$ & $\mathbf{6}$ & $\mathbf{7}$ & $\mathbf{8}$ & $\mathbf{9}$ & $\mathbf{1 0}$ & $\mathbf{1 1}$ & $\mathbf{1 2}$ & $\mathbf{1 3}$ & $\mathbf{1 4}$ \\
\hline Acontosceles & 1 & 0 & 1 & 0 & 0 & 0 & 2 & 0 & 1 & 0 & 0 & 0 & 0 & 0 \\
Pseudeucinetus & 1 & 0 & 1 & 0 & 1 & 1 & 1 & 1 & 1 & 1 & 0 & 0 & 0 & 0 \\
Mexico & 1 & 0 & 1 & 0 & 0 & 1 & 1 & 1 & 1 & 0 & 1 & 1 & 1 & 1 \\
Martinius & 1 & 0 & 1 & 1 & 1 & 0 & 1 & 1 & 1 & 0 & 0 & 0 & 1 & 1 \\
Limnichus & 0 & 1 & 0 & 0 & 0 & 0 & 0 & 0 & 0 & 0 & 0 & 0 & 0 & 0 \\
\hline
\end{tabular}

